\title{
Multi-spectral and Thermography Imaging Techniques for the Investigation of a 15th Century Wall Painting
}

\section{Marco Ricci}

University of Calabria: Universita della Calabria

\section{Stefano Laureti}

University of Calabria: Universita della Calabria

Hamed Malekmohammadi

University of Perugia

\section{Stefano Sfarra}

University of L'Aquila

\section{Marcello Melis}

Profilocolore srl

\section{Giorgia Agresti}

University of Tuscia

\section{Luca Lanteri}

University of Tuscia

\section{Claudia Colantonio}

University of Tuscia

\section{Giuseppe Calabrò}

University of Tuscia

Claudia Pelosi ( $\square$ pelosi@unitus.it)

Department of Economics, Engineering, Society and Business Organization (DEIM), University of Tuscia, 12 Viterbo, Italy; https://orcid.org/0000-0002-1338-5267

\section{Research article}

Keywords: Hypercolorimetric multispectral imaging, Pulse-Compression Thermography, wall 42 paintings, restoration, underdrawing, painting stratigraphy

Posted Date: October 29th, 2020

DOl: https://doi.org/10.21203/rs.3.rs-97372/v1 
License: (c) (i) This work is licensed under a Creative Commons Attribution 4.0 International License. Read Full License 


\section{Multi-spectral and thermography imaging techniques 2 for the investigation of a $15^{\text {th }}$ century wall painting}

3 Marco Ricci ${ }^{1}$, Stefano Laureti ${ }^{1}$, Hamed Malekmohammadi ${ }^{2}$, Stefano Sfarra ${ }^{3}$, Marcello Melis ${ }^{4}$, 4 Giorgia Agresti ${ }^{5}$, Luca Lanteri ${ }^{5}$, Claudia Colantonio ${ }^{5}$, Giuseppe Calabrò ${ }^{\text {, Claudia Pelosi }}{ }^{5^{*}}$

1 Department of Informatics, Modeling, Electronics and Systems Engineering, University of Calabria, Rende (CS), Italy; marco.ricci@unical.it; stefano.laureti@unical.it

2 Department of Engineering, Polo Scientifico Didattico di Terni, University of Perugia, Terni, Italy; hamed.malekmohammadi@unipg.it

3 Department of Industrial and Information Engineering and Economics, University of L'Aquila, L'Aquila, Italy; stefano.sfarra@univaq.it

4 Profilocolore S.r.l., Rome, Italy; marcello.melis@profilocolore.it

5 Department of Economics, Engineering, Society and Business Organization (DEIM), University of Tuscia, Viterbo, Italy; agresti@unitus.it; llanteri@unitus.it; c.colantonio@unitus.it; giuseppe.calabro@unitus.it; pelosi@unitus.it

* Correspondence: pelosi@unitus.it; Tel.: +39-333-2877468 (C.P.)

17 Abstract: When planning the restoration of an artwork, the good practice involves the evaluation of the item healthiness before starting the common operation of cleaning, consolidation, etc., possibly through non-invasive techniques that supply meaningful information about the whole item. Motivated by this need, a plethora of imaging techniques are used in cultural heritage diagnostic typically borrowed from other applications - e.g. medical diagnostics, nondestructive testing, etc., and then tailored for inspecting cultural heritage objects. In the inspection of a painting, hyper- and multi- spectral techniques are commonly used to analyze the outer layers (varnish, pictorial and drawing) while X-ray, tomography, and many other can be employed to investigate its inner structure. Although highly desirable, a single technique providing all the info about a painting is still not available, thus it is of great interest defining protocols that could optimally exploit the complementarities of a limited number of techniques. To this aim, the present paper shows the combined use of the Hypecolorimetric Multispectral Imaging (HMI) and that of the Pulse-Compression Thermography $(\mathrm{PuCT})$ on a $15^{\text {th }}$ century wall painting attributed to the Italian artist Antonio del Massaro, also known as Pastura, and representing the Madonna with the Child and the Saints Jerome and Francis. In particular, HMI is a multispectral imaging method working from the ultraviolet to the near infrared region, exploiting advanced processing based on artificial intelligence to define hypercolorimetric coordinates. Such approach guarantees a thorough 
analysis of the outer layers, underlining previous restorations, varnish alterations and allowing the pigments to be classified from a comparison with a large database. The PuCT method adopted here has been tailored for the specific needs of artworks' inspection and it allows for a safe imaging of the multilayer structure of paintings, and hence the stratigraphy analysis, through a suitable processing of the time-domain thermal response. The capabilities and the complementarities of the two techniques, whose info can also be fused through postprocessing techniques, are illustrated in detail in this paper. A false-color imaging approach is also proposed to improve the readability and analysis of the thermography results.

Keywords: Hypercolorimetric multispectral imaging; Pulse-Compression Thermography; wall paintings; restoration; underdrawing; painting stratigraphy.

\section{Introduction}

In developing restoration, conservation and preservation plans for Cultural Heritage $(\mathrm{CH})$ items, diagnostics is nowadays a key ingredient. The knowledge of both the original and restoration materials, of the construction techniques, and of the stratigraphy of the artwork is requested by conservators to define any potential interventions. Among numerous diagnostics tools, imaging techniques have become widely applied in $\mathrm{CH}$ as they provide information on the materials and the structure of the artworks in a non-invasive and non-destructive way. Such information is useful for conservators to choose the most appropriate intervention decision during a restoration work [1-16]. Imaging techniques can provide a complete knowledge of the surfaces in a fast and reliable way without the need for sampling micro-chips of materials for laboratory analysis, a fact that is in general highly desirable or mandatory in some cases [13-16].

When dealing with paintings, a thorough diagnostic approach relies on (i) the integration of data collected from different imaging techniques, (ii) the exploitation of their complementarities in terms of spectral range and/or physical principles, and (iii) the potential combination of the relative 
outputs via digital imaging processing tools. It is important to note that data integration and fusion can strongly support traditional analytical methods, yielding a comprehensive diagnosis of the painting state of conservation and reducing any ambiguities due to the use of a single diagnostic method $[2,9-11,14,16-17]$.

Hyperspectral (HS), multispectral (MS), and any other imaging techniques processing spectral data are the preferred ones for studying the outer layers of painting such as the varnish, the pictorial stratum, the dirt - if present - and the underdrawings. Thus, starting from ultraviolet (UV), passing by visible (VIS), and reaching infrared (IR), the outer layers of a painting can be inspected. In particular, UV reflectance and fluorescence are employed for evaluating the condition of the varnish layer, for identifying possible retouching and over-paintings; fluorescence can also aid in the characterization of the materials (varnish, pigments and binders). The analysis of the reflected light in the VIS range, especially using raking light, highlights the artist's technique (brushstrokes, impastos), the presence of flaking paint or cracks, and it can also show areas requiring special care for being faithfully preserved. Finally, images in the near IR range are used for the analysis of the inner layers - near IR light can penetrate the pictorial layer and make the underdrawing and possible pentimenti being visible due to the high reflectance of carbon-based materials. This is possible since most of the historical pigments, binders, and varnish are partially transparent in the near IR (around $1000 \mathrm{~nm}$ of wavelength). However, the transparency of the outer layers to the near IR lights depends on many factors such as the layer thickness and chemical composition, a fact that makes the imaging of the underdrawing layer challenging. Another powerful exploitation of the IR radiation for painting analysis is represented by the HS imaging techniques that use the retrieved pixelwise spectral information to classify the pigments and to map them over the inspected painting surface. Hyperspectral cameras split the range of sensitivity of the sensors in hundreds of bins for an accurate reconstruction of the reflected IR spectrum. In painting inspections, near $(900-1700 \mathrm{~nm})$ or short-wave (1000-2500 nm) IR hyperspectral camera are mainly used - many of the overtones and the combination of vibrational bands characteristics of the inorganic pigments used in historical 

paintings fall in these ranges. It should be noted that the application of HS imaging in the middle (3000-5000 nm) IR has also been recently reported to classify organic compounds [18].

The main drawback of HS imaging is a practical one: hyperspectral cameras are still very expensive and need for a scanning stage to output images of the surface - the spectral scanning is usually realized by combining a standard IR camera with a monochromator or with a diffraction grating. These facts hamper the use of HS imaging for in situ artworks inspection. Further, for what mentioned above, HS imaging should be anyway combined with UV and VIS imaging methods. As a consequence, the possible engineering of a single technique capable of providing info within the mentioned electromagnetic spectra is highly desirable and would be of a great value from a practical point of view. In this framework, HMI processes information from the near UV to the near IR. The here-employed system relies on a 36 megapixels reflex Nikon camera modified to work in the 300-1000 nm extended range combined with proper choice of flash lamps and optical filters. The images obtained are then represented into a 7D hyper-colorimetric space. Such coordinate system extends the concept of the common 3D colour space used in colorimetry, i.e. the CIE XYZ standard, or the more common RGB, by defining seven hyper-colorimetric coordinates in which a coordinate is related to the near UV range and three ones to the near IR range. By combining artificial intelligence techniques with a proper calibration procedure, it is possible to fully exploit this augmented colour space to perform all the tasks discussed above [19-21].

Regarding the evaluation of the whole painting stratigraphy, i.e. from the varnish to the support (panel, canvas, wall, etc..), the number of possible techniques is even larger: X-ray imaging is largely employed, 2D and 3D XRF imaging are often used for identifying materials' chemical composition. In addition, medical computer tomography techniques, terahertz time resolved (TTR) imaging, optical coherence tomography (OCT) and nuclear magnetic resonance have recently enlarged the range of methods for such purpose [22-24].

In this framework, InfraRed Thermography (IRT) represents a robust technique for the inspection of $\mathrm{CH}$ items [25-26]. Also in this case, a trade-off between information amount, cost and 
111 measurement complexity (measurement time, mechanical equipment, computational costs, etc.)

112 should be found. IRT is relatively easy to be performed in situ, providing imaging without the need

113 of imaging reconstruction algorithms and it can be operated on large areas moderately easy.

114 Moreover, IRT does not require a continuous translation stage as for the point-wise imaging

115 equipment such as TTR, XRF, OCT, NMR, etc., and it does not involve any hazardous source. The

116 costs are not as low as the typical equipment for IR reflectometry, but are among the cheapest ones

117 within the above-mentioned techniques.

118 On the other hand, IRT does not reach the depth resolution of other techniques such as TTR and

119 OCT, but it can inspect the support up to depth of several millimetres - a few centimetres in the

120 case of wall paintings provided that a suitable excitation scheme is used. In addition, recent

121 developments in IRT technique have increased its effectiveness for artworks inspection and reduced

122 the risk of any alteration of the artworks due to the thermal stimulus [27-28]. In particular, the use of

123 the so-called Pulse-Compression Thermography $(\mathrm{PuCT})$ procedure combined with a pseudo-noise

124 modulated heating stimuli demonstrated to be effective even with a very small increment in the

125 sample surface's temperature $\left(\sim 1^{\circ} \mathrm{C}\right)[29-30]$.

126 For the mentioned reasons, the combined use of PuCT and HMI is very promising for in situ

127 inspections of paintings: the tailored hardware and the advanced processing and postprocessing

128 algorithms provide complimentary information to art historians and restorers, and their contextual

129 use allows for investigating the paintings' stratigraphy from the varnish to the support. The output

130 of the two methods can be easily fused by image processing tools and post-processing algorithms.

131 The first example of the combined application of the two techniques was recently reported in

132 the literature - HMI and PuCT were used for inspecting two historical panel paintings of the

133 renaissance period, realised by Andrea Mantegna and from Michelangelo's workshop [31].

134 In the present work, HMI and PuCT are applied together for the first time on a detached wall

135 painting under restoration in the Laboratories of the five-year course in Conservation and

136 Restoration of Cultural Heritage (LMR/02) of University of Tuscia, Italy [32]. 

the convent of Santa Maria del Paradiso in Viterbo, central Italy [33-34]. of the lunette was probably due to its bad state of conservation caused by the exposure to

144 weathering and acts of vandalism [35]. In fact, large grouts are visible in the photographs of the 145 beginning of $20^{\text {th }}$ century confirming its bad state of conservation and the need for interventions [36]. The ancient restoration interventions were made with both unsuitable materials and techniques such as the mimetic reintegration, hampering in turn the correct readability of the artwork and of its original painting. In accordance with the Superintendence and the responsible of the Civic Museum, it has been thus decided to perform a restoration aimed at recovering the original appearance of the painting at the best. Consequently, in 2016 the lunette has been brought in the restoration 151 laboratories of University of Tuscia for starting the intervention.

153 photography aimed at mapping the superimposed materials, the grouts, the lacunae and in general 154 the non-original areas being very well visible under ultraviolet fluorescence photography. The 155 image under UV radiation showed diffuse blue fluorescence probably due to the presence of glue used for the detachment of the lunette [36-37]. Grouts and cracks have been also well-highlighted by the UV image [32]. Moreover, in order to characterise the blue fluorescent material visible under UV

158 radiation, Fourier transform infrared analysis was performed. This revealed that the yellowed 159 surface material was made of protein glue. The main signatures of glue have been observed in the 160 infrared spectrum at cm-1: 3289, 3064, 2930, 1660, 1542, 1373, 1313, 1246, 1033 [38-39]. Other bands in 161 the spectrum have been associated to calcium carbonate (1424 and $\left.876 \mathrm{~cm}^{-1}\right)$ and gypsum $\left(1152 \mathrm{~cm}^{-1}\right)$ 
[32]. This preliminary analysis has been fundamental both to address the first cleaning choices of restorers and to start the intervention.

After this, further investigations were performed by combining $\mathrm{HMI}$ and $\mathrm{PuCT}$ to obtain information about the painting materials and the stratigraphic sequence, the last one being a highly-inhomogeneous mix of both original layers and new grounds added during the detachment of the lunette from the church of Santa Maria del Paradiso. The achieved results are illustrated in the following sections, demonstrating the high potential of this integrated approach to become a standard methodology in the preliminary study of the artworks to be restored.

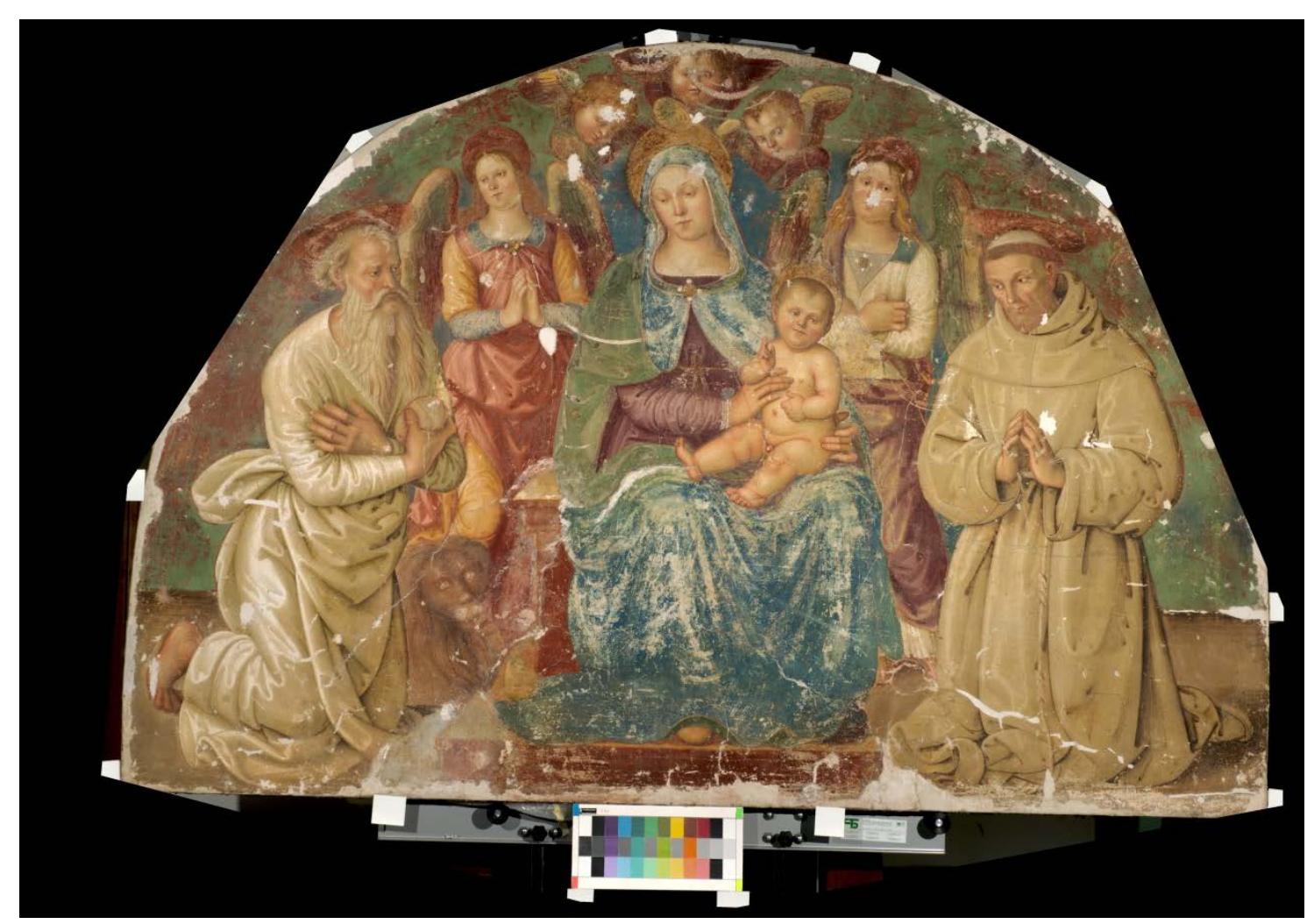

Figure 1. The lunette with Madonna and the Child enthroned between the angels and the Saints

173 Jerome and Francis (AD 1490), attributed to the painter Antonio del Massaro known as Pastura (1450-1519). The calibrated visible image with the colour checker and the white patches used for HMI acquisition is shown in the figure. 


\subsection{Hypercolorimetric Multispectral Imaging (HMI)}

HMI was performed through a Nikon D810FR 36 Megapixel camera, modified to obtain full range spectral reflectance measurements. Nikon SB910 xenon flashes without their front plastic lenses were used for lighting the painting, thus allowing the UV wavelength to be emitted as well. The UVF was then obtained by filtering the flashes light with a UV band-pass filter with a spectral cut at $380 \mathrm{~nm}$, and UV-IR cut filter $(400-700 \mathrm{~nm})$ in front of the camera. The HMI image processing system consists of two main software tools, i.e. SpectraPick ${ }^{\circledR}$ for the image calibration and PickViewer ${ }^{\circledR}$ for the image analysis $[13,19-21,31]$. The calibration of the images was achieved by placing radiometric references just below the painting. In particular, various white patches and a sample with 36 patches of colour-checkers built using colour samples from the NCS - Natural Colour System ${ }^{\circledR \odot}$ catalog were placed just below the painting, see Fig.1. The spectral reflectance of the references was measured in the range $220-1050 \mathrm{~nm}$ at Profilocolore laboratory, with $0.7 \mathrm{~nm}$ accuracy (Instrument System Spectroradiometer CAS 140 CT and dark room). The calibration procedure outputs a single AdobeRGB TIFF 16 bit colour image and seven monochromatic images in 16 bit TIFF format, containing the spectral reflectance values at 350, 450, 550, 650, 750, 850 and 950 $\mathrm{nm}$. The last three values were used to define the IR1, IR2 and IR3 images respectively. The precision achieved in the reflectance measurement across the whole 36 megapixels image is higher than $95 \%$ and the colour error less than CIE2000 $\Delta E=2$ for the colour image [13]. The whole calibration and alignment process require a few minutes and it can be performed in situ for an immediate results analysis.

After the image acquisition and calibration, multispectral images were processed through the HMI software PickViewer ${ }^{\circledR}$, developed by Profilocolore. The PickViewer ${ }^{\circledR}$ software provides powerful image processing tools able to reveal relevant information. Further, it allows gathering information on hidden data from the images acquired with SpectraPick system, containing spectral reflectance and colour coordinates for each of the 36 megapixels of the captured scene. Data are 
calibrated and they are absolute in values, thus only depending on the spectral characteristics of the surface. Several kinds of analyses are possible with PickViewer ${ }^{\circledR}$, such as:

- $\quad$ adding and integrating any other imaging data (fluorescence, $X$-ray, thermal etc.);

- multichannel images viewer; any pixel colorimetry and spectral reflectance read-out;

- mapping by colour, spectra, arbitrary channels;

- principal components analysis (PCA);

- contrast enhancement through digital imaging processing algorithms;

- neural network based clustering;

- colour and spectral signature database;

- two ways mapping by database entry;

- any channel to RGB false colours visualization;

- channels math, indexes and normalised contrast;

- calibration and colour-checker test.

Each relevant result can be saved as image in TIFF, png or jpeg format. Results saved in TIFF format can be reloaded as further derived channels and used combined with all the others [19].

\subsection{Pulse-Compression Thermography (PuCT)}

The experimental setup used for the PuCT is the same detailed in previous published papers, wherein also an extended theoretical base of the technique can be found [32-34]. In particular, the signal generation/acquisition was managed by Labview ${ }^{\mathrm{TM}}$ software. Thermograms were collected through a Xenics Onca-MWIR (3.6-4.9 $\mu \mathrm{m})-\mathrm{InSb}$, having a resolution of $320 \times 240$ pixels, a frame rate of $40 \mathrm{~Hz}$, and connected to a NI-1433 Camera Link Frame Grabber. The distance between the painting and the camera was about $70 \mathrm{~cm}$. Eight light emitting diode (LED) chips have been used as the heat sources, each one with a maximum nominal electrical power of $50 \mathrm{~W}$. Note that the LEDs were not used at their maximum power - an overall electrical peak power of about $250 \mathrm{~W}$ was reached to get the reported results. The pseudo-noise code driving the LED chips consisted in a repetition of two Legendre sequences, each one of 47 bits. The duration of each bit was $1 \mathrm{~s}$, thus 
resulting in an overall excitation of $94 \mathrm{~s}$. During this time, the LEDs were switched on for about half of the overall excitation time, so that an overall electrical energy of $\sim 12 \mathrm{~kJ}$ was delivered. Note that the camera and the heating source were on the same side with respect to the inspected painting, thus 231 the PuCT was performed in reflection mode. The coded excitation voltage signal driving the LEDs was provided by a TDK Lambda GEN 750W power supply. The frame grabber and the power supply were synchronously driven by the signals provided by a National Instrument PCI-6711 Arbitrary Waveform Generator (AWG) board. Both the AWG board and the frame grabber were connected to a central PC/DSP Unit.

A thorough description of the PuC algorithm lies beyond the scope of this work, therefore the reader is referred to [28,30-31] for a deeper understanding of the whole procedure. For the sake of clarity, some fundamentals aspects are worth to be here recalled:

239 1) For the here-employed setup, the reconstructed time trend of each pixel after the application of 240 the PuC algorithm corresponds to that achievable by exciting the sample with an equivalent 241 rectangular pulse of $1 \mathrm{~s}$ duration. The advantage of using PuC instead of a pulsed excitation is 242 that this fictitious single pulse carries the energy of the entire pseudo-noise Legendre sequence, 243 so that the response after $\mathrm{PuC}$, and hence the thermograms, are characterized by a good 244 signal-to-noise ratio (SNR) even by using low peak power values. It must be stressed that such 245 aspect is crucial in the inspection of irreplaceable items as the artworks: while a short high-power 246 excitation pulse could damage the painting by inducing thermochromism or thermal/mechanical stress, the use of a pseudo-noise excitation spread instead the energy within a longer time, making the temperature rise of the sample being smooth and lower in magnitude. After PuC, a 249 fictitious larger and faster temperature increment is instead achieved exploiting the mathematical 250 properties of the coded excitation.

251 2) It has been shown in [31] that the use of the Hilbert transform and of the derived time-phase 252 feature from PuCT signals can help to highlight some characteristics of the support, such as the 253 wood grain, grouts, etc.. Here, the same processing is applied to the PuCT data to enhance the 
254 sensitivity in the inspection of sub-surface layers. Thus, three different time-domain features will

255 be here shown. In particular: "Emissivity" - is the amplitude of the time signal of each pixel 256 retrieved after $\mathrm{PuC}$ and it is an indirect measure of the pixel thermal emissivity, which can be 257 related to the pixel surface temperature by a proper calibration; "Hilbert" - is the output of the 258 Hilbert transform applied pixelwise to the "Emissivity" trends; "Time-phase" - is the function 259 that for each time instant $t$ outputs the argument of the complex number $c(t)=$ Emissivity $(t)+$ $260 \quad i * \operatorname{Hilbert}(t)$ in time domain, with $i$ being the imaginary unit.

261 3) As for HMI, PCA has been applied to the time series of thermograms produced by imaging both the Emissivity and the Hilbert features. As can be seen in the next Section, PCA allows for evidencing some specific characteristics of the time-series while reducing the number of images to be analysed. This can be very useful for a first analysis of the sample to detect anomalies, while for a quantitative analysis the processing of the image time-series is necessary.

4) An alternative way for presenting the thermography results has been here explored, which is based on using the three abovementioned features, i.e. emissivity, Hilbert and time-phase, to generate colour images. In particular, $\mathrm{RGB}$, and $\mathrm{YCbCr}$ colour spaces have been explored by relating each colour coordinate to the each of the three features.

270 As a final remark, it is important to highlight that the PuCT images showed below were obtained 271 after merging thirteen thermal acquisitions. Multiple acquisitions were performed to obtain a good trade-off between the tested painting surface and the need for assuring enough spatial resolution of the captured thermograms. As an example of the procedure, Figure 9a depicts the image of the thermal emissivity estimated after 1 second from the beginning of the reconstructed thermal pulse. Some discontinuities between the images corresponding to the various acquisitions can be seen even after some preliminary image processing. Certainly, the merging procedure can be further improved with a proper calibration, but this will be addressed in a next work.

278 The current results are anyway enough satisfactory to be exploited for an evaluation of the state of conservation of a painting. 


\section{Results and Discussions}

\subsection{Hypercolorimetric Multispectral Imaging (HMI)}

The seven calibrated spectral bands were analysed in PickViewer ${ }^{\circledR}$ software and some processing tools were applied to the images in order to gain further diagnostic information. the presence of preparatory drawing and possible pentimenti, especially in the restored areas where different and superimposed materials are found to be highly mixed. PCA has been widely used for art conservation applications, either as a stand-alone technique or to reduce the dimensionality of datasets using linear algebra techniques prior to another classification algorithm whereby multiple variables are analysed to evaluate the contribution of each variable to an observed result [40-41]. Clustering techniques can classify data based on a comparison of the spectral character of each point

291 in the image with the spectral character of every other point; this permits patterns or clusters to emerge from the clustered data, thus pointing out areas of compositional similarity and returning a spatial distribution of components [42]. 


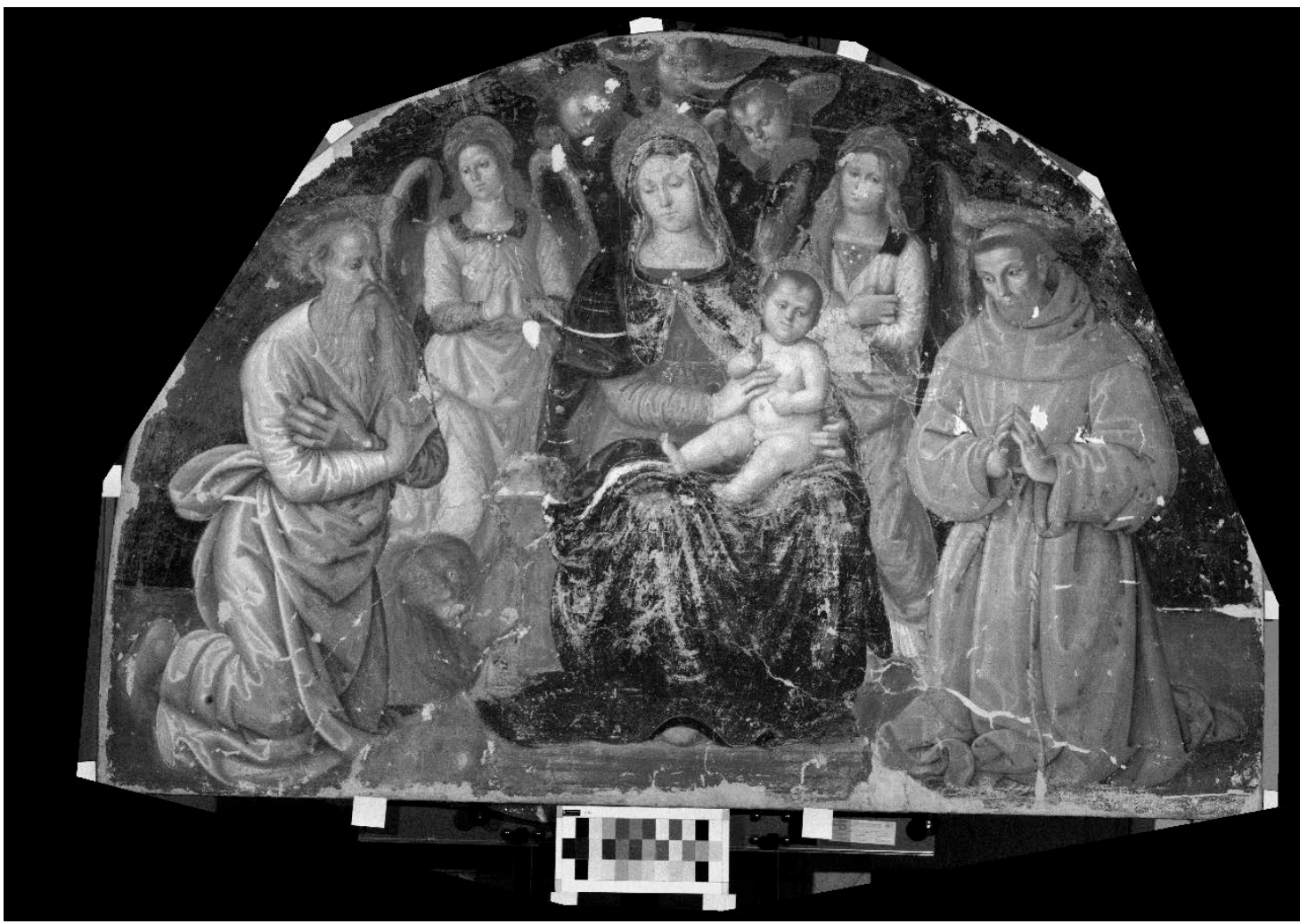

Figure 2. The HMI infrared calibrated image at $850 \mathrm{~nm}$ (IR2) showing the preparatory drawing used for

297 the construction of the painting.

In the detail of the foot of Saint Jerome in the IR2 image, a pentimento can be observed (Fig. 3) on

299 the left side, where a different original outline was traced for drawing the foot. Figure 3 shows also the graphical user interface (GUI) of PickViewer ${ }^{\circledR}$ software: on the left an image or a selected area of the image is shown, while the processing results, according to the selected function, are visible on the right part. Extensive micro-cracking has been highlighted in correspondence of the Virgin's face by applying PCA to the images in the IR region (IR1, IR2 and IR3, see Fig. 4).

Another interesting processing tool of Pickviewer $^{\circledR}$ is Spectral Similarities that allows for comparing the spectral reflectance of two different points on the examined surface. It was applied, for example, to the red colour in the Virgin' garment and in that of the angel at the right side of the Virgin (Fig. 5). The values of colour coordinates and of reflectance show the high similarity of the two point colour, suggesting a possible equal composition in terms of pigments. 
311 obtained by combining calibrated R, G, B and IR channels (Fig. 6) [43-45]. The possibility of 312 obtaining the IRFC image in a very short time by simply combining the channels, is a great 313 potentiality of PickViewer ${ }^{\circledR}$ software. For the blue pigment of the Virgin's garment, the use of azurite 314 was hypothesized on the base of its characteristic deep blue colour in IRFC. The sky and parts of the 315 vest of the Virgin have a particular green colour in the visible; in IRFC, they assume a light blue hue 316 making probable its attribution to malachite. Considering the bad state of conservation of the 317 artwork after a long exposition to weathering, a preferential degradation caused by humidity with a 318 transformation of azurite into malachite or other green copper-based compounds seems very likely, 319 rather than the application of a green pigment in areas meant to be blue-coloured [46]. Portion of 320 unaltered azurite are in fact clearly visible in the background sky behind the head of the Virgin and 321 in the lower edge of the sky as well (Fig. 7).

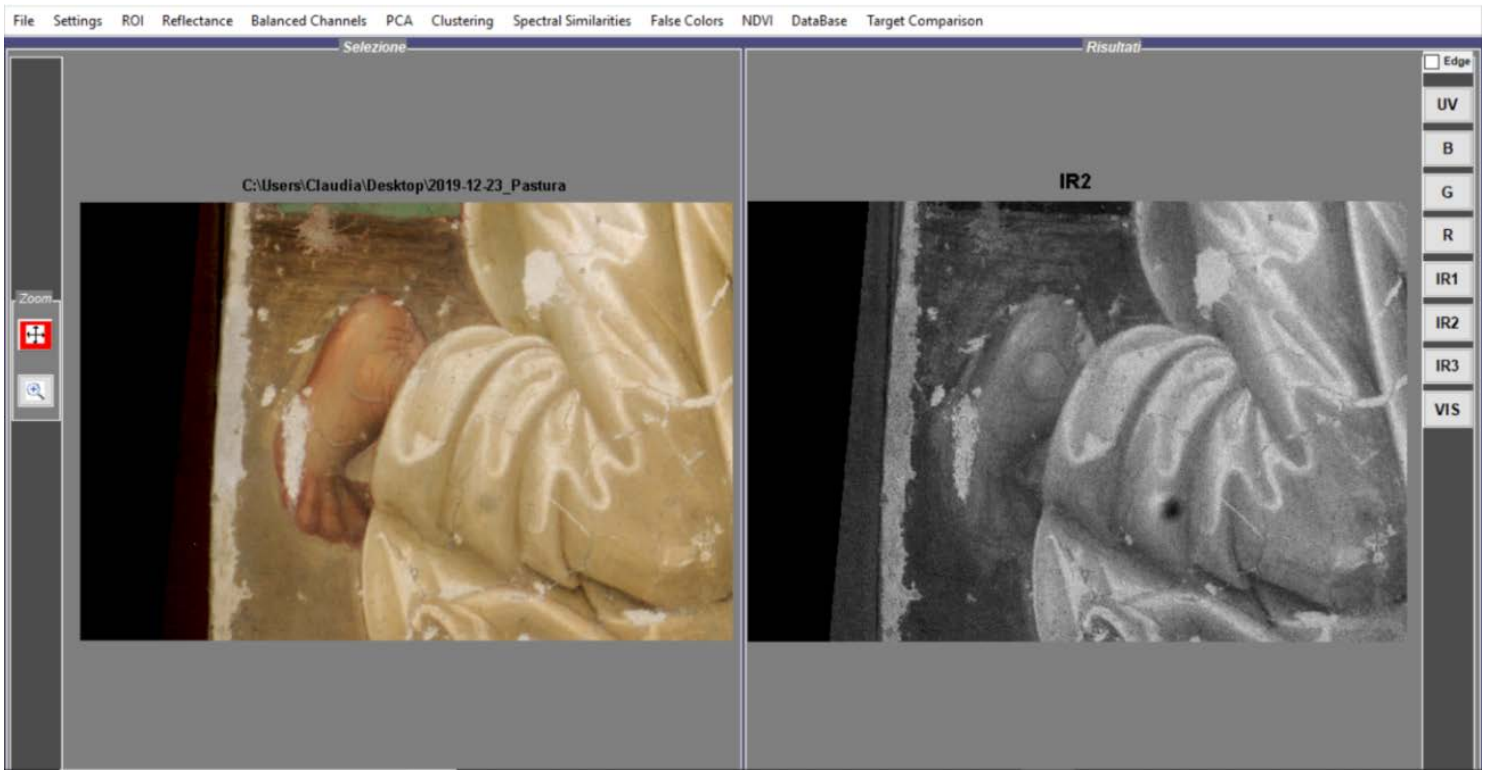

Figure 3. A detail of the HMI infrared calibrated image at $850 \mathrm{~nm}$ (IR2) showing the pentimento in the drawing of Saint Jerome foot. 


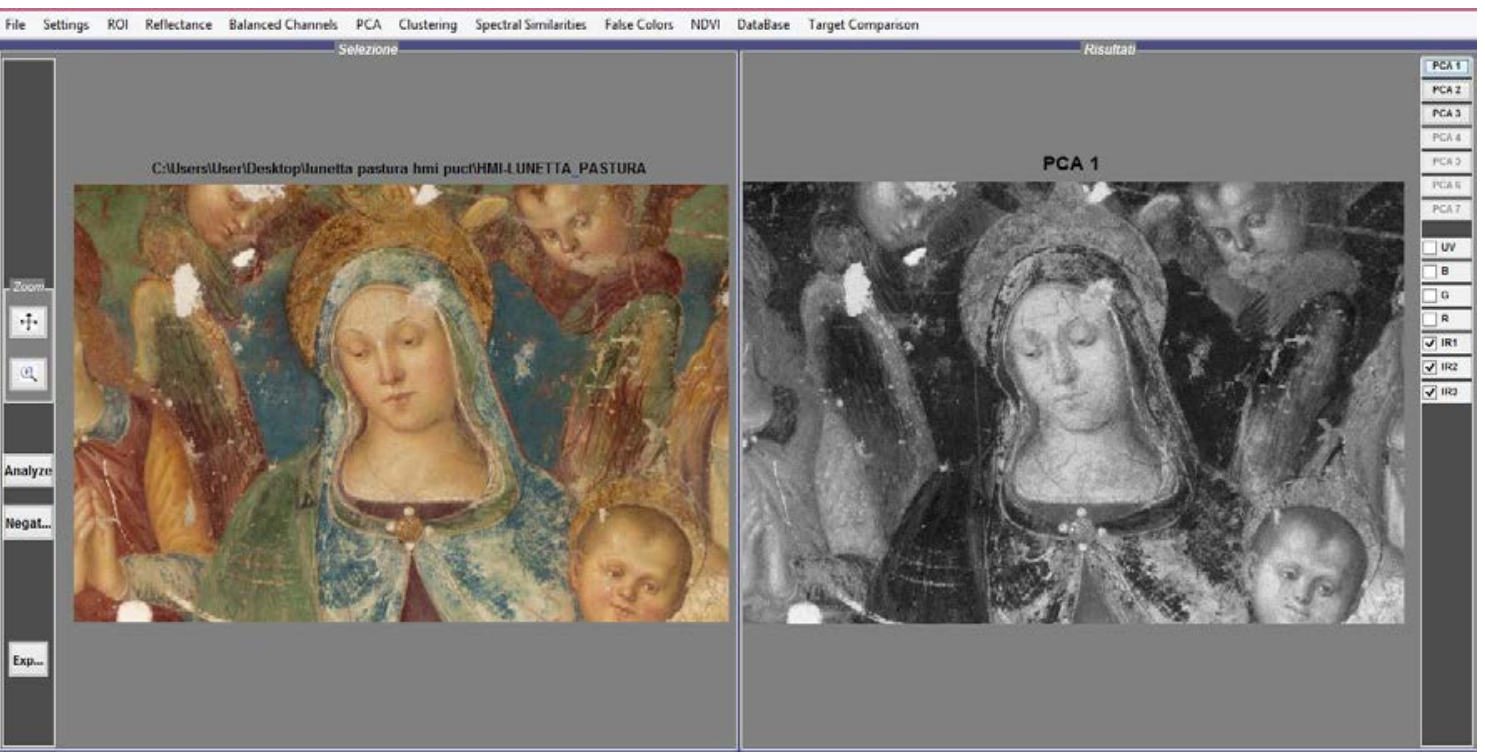

Figure 4. PCA applied to IR1-IR2-IR3 calibrated images showing an extensive cracking in correspondence

328 of the Virgin's face and neck

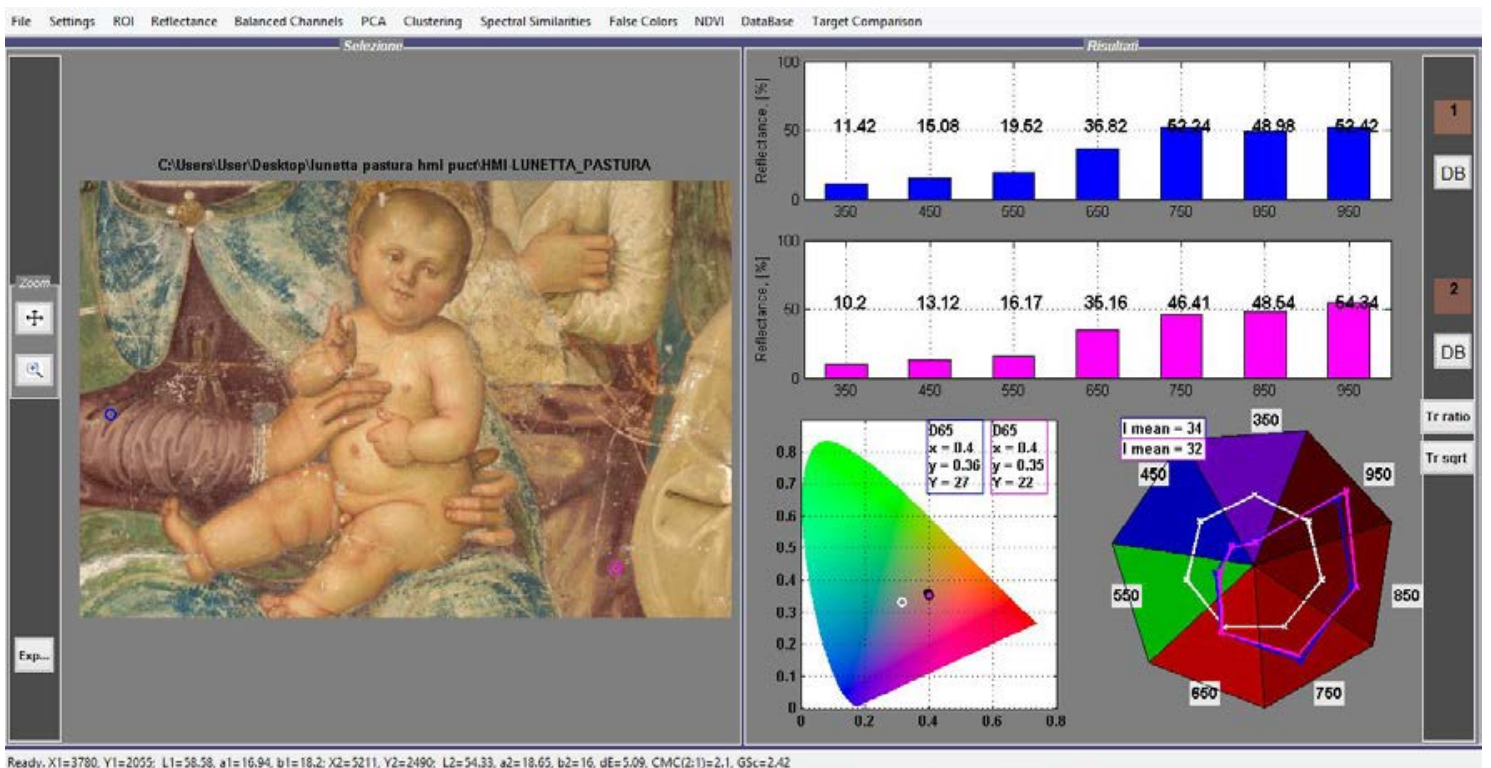

330 Figure 5. Spectral Similarities tool applied to a point on the arm of the Virgin garment and on the Angel's

331 dress. High similarity is found both in terms of reflectance values and of colour coordinates.

In order to investigate this possibility in a non-invasive way, a map of spectral similarity was

333 built on the base of the 7-bands curve of spectral reflectance measured in a $9 \times 9$ pixels area in the blue

334 part of the Virgin's dress, as shown Fig. 8. The output showed on the right of the visible image in the

335 software's GUI, highlights a correspondence between the blue pigment of the vest of the Virgin and

336 the one used to paint the sky, supporting the hypothesis of the use of azurite in all the blue areas. 
The painting layer of azurite used for the sky is applied over a coloured ground layer probably

338 based on red earth (hematite) or charcoal black (morellone), usually used for the application of azurite

339 in wall paintings, as described in scientific literature [47].

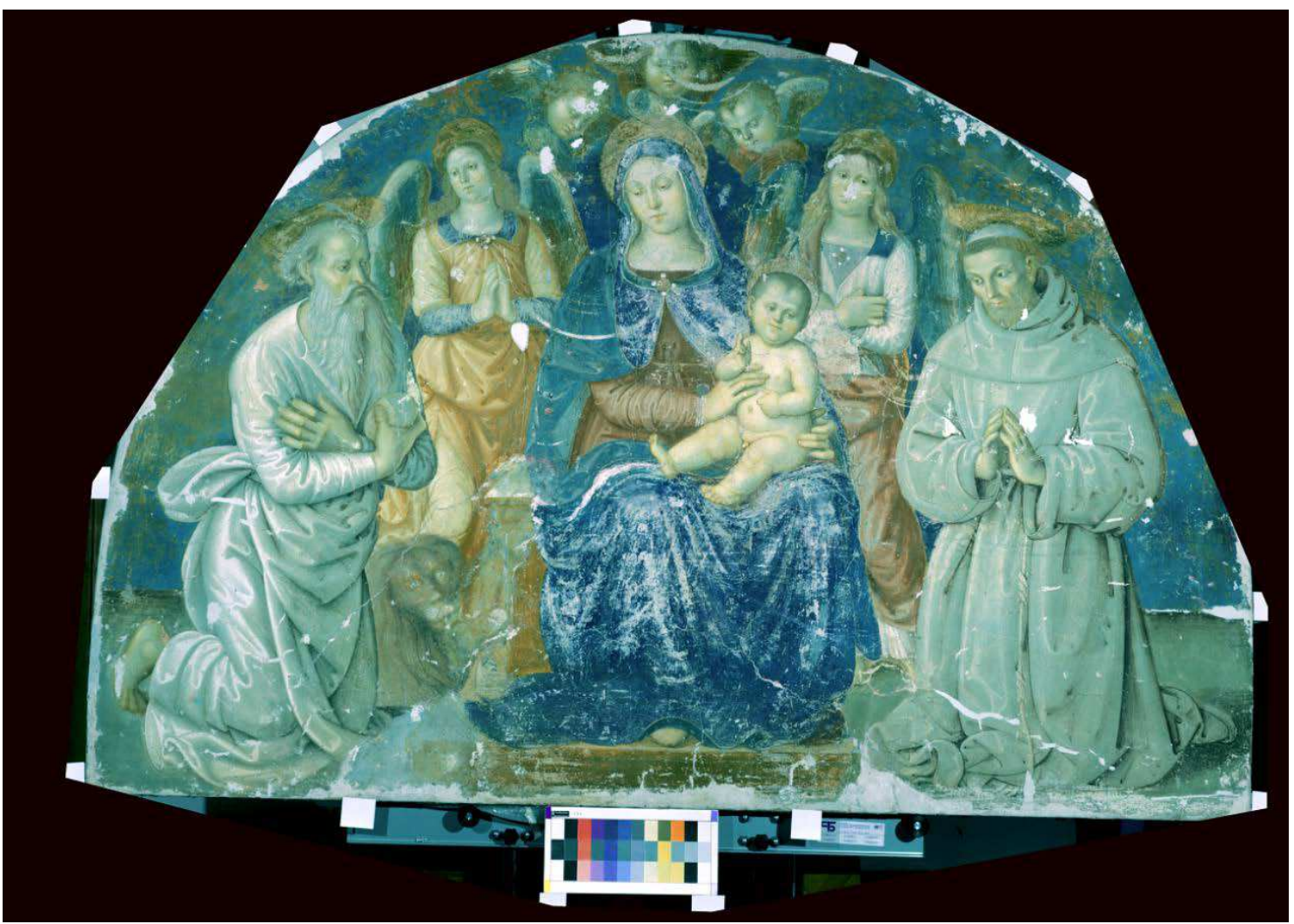

$342 \quad$ Figure 6. Infrared false colour image obtained through PickViewer ${ }^{\circledR}$.

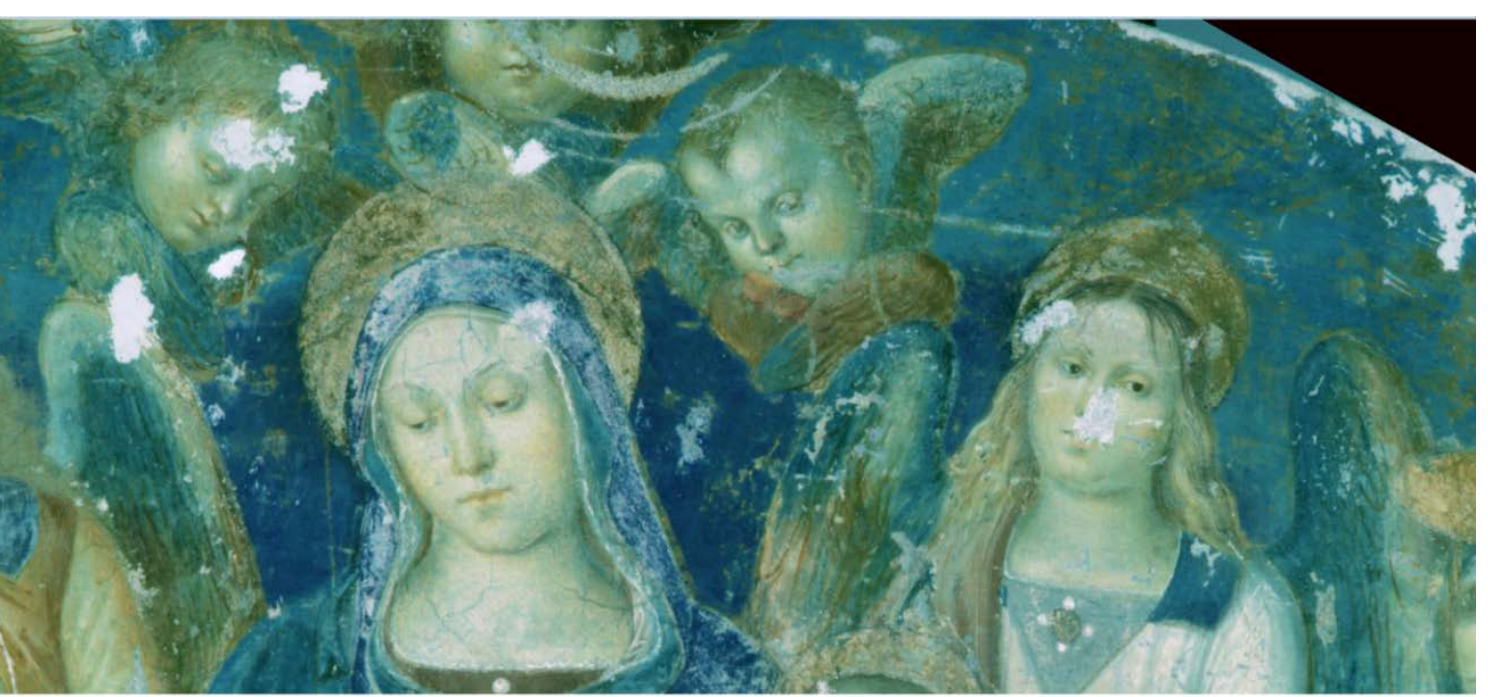

Figure 7. Detail of IRFC image showing the blue portion of the probable unaltered azurite in the

345 background sky behind the head of the Virgin. 


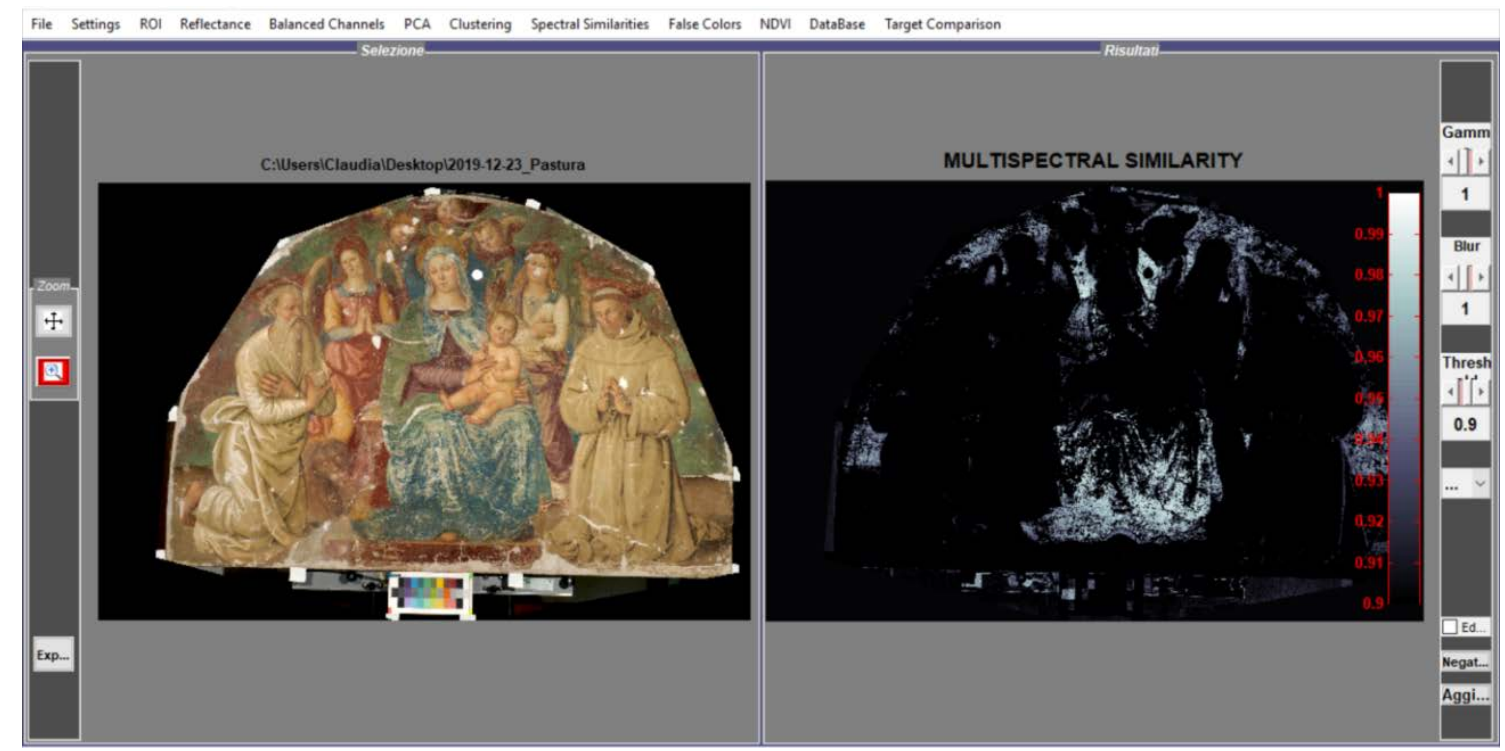

Figure 8. Multispectral similarity mapping of azurite.

The reported results were obtained by applying pixelwise the Pulse-Compression (PuC)

algorithm over the acquired thermograms, which has been described in detail in Sect. 2.2.

The IR2 band (850 nm, Fig. 2) gives some information on the preparatory drawing of the scene,

Jerome. Concerning the infrared PuCT analysis, the results highlight many interesting details of the surface and of the stratigraphy. Detachments, gold coating and different restoration works appear as brighter areas in emissivity images. Note that the brighter the area, the lower the emissivity. This can be seen in Fig. 9 reporting the emissivity image corresponding to $t=1 \mathrm{~s}$, at which the fictitious excitation pulse stops, and the temperature decay starts. Typically, this is the time instant that better shows the details of the pictorial layer, since during the excitation the light is absorbed differently by the various colours, leading to a variation of the surface temperature over the sample. 
366 and Saint Jerome appears as a well-delimited cold area, while Saint Jerome's right arm is hotter than

367 the rest of the figure. It can be noticed that the same arm exhibits an anomalous brilliance in the IR2

368 and in false colour images (Figures 2 and 6), probably due to the use of different materials and

369 painting techniques.

370 Then, different features become more visible as time elapses, as there is a direct link between

371 the thermal responses of layers at deeper depths within the tested materials and the flow of time.

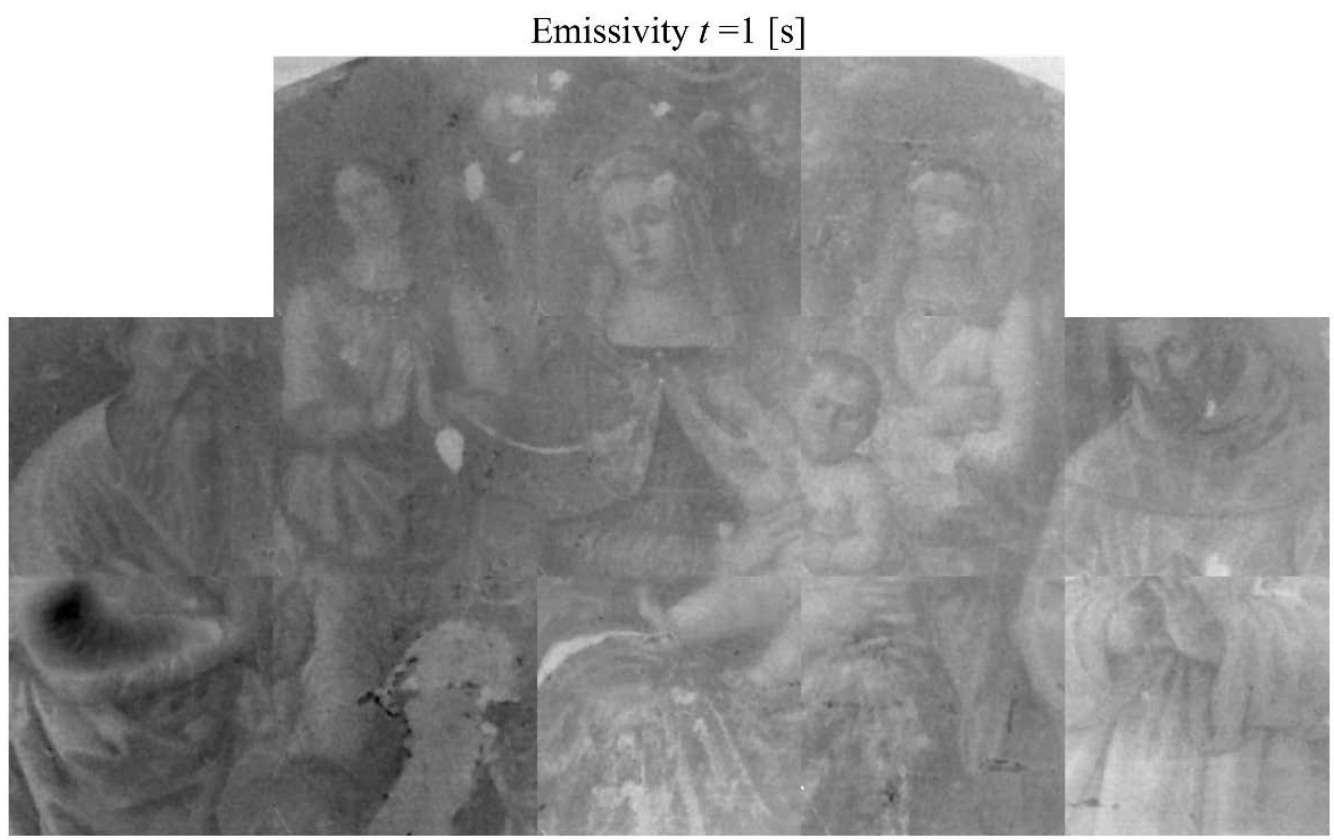

Figure 9. PuCT emissivity image obtained at $t=1 \mathrm{~s}$. 


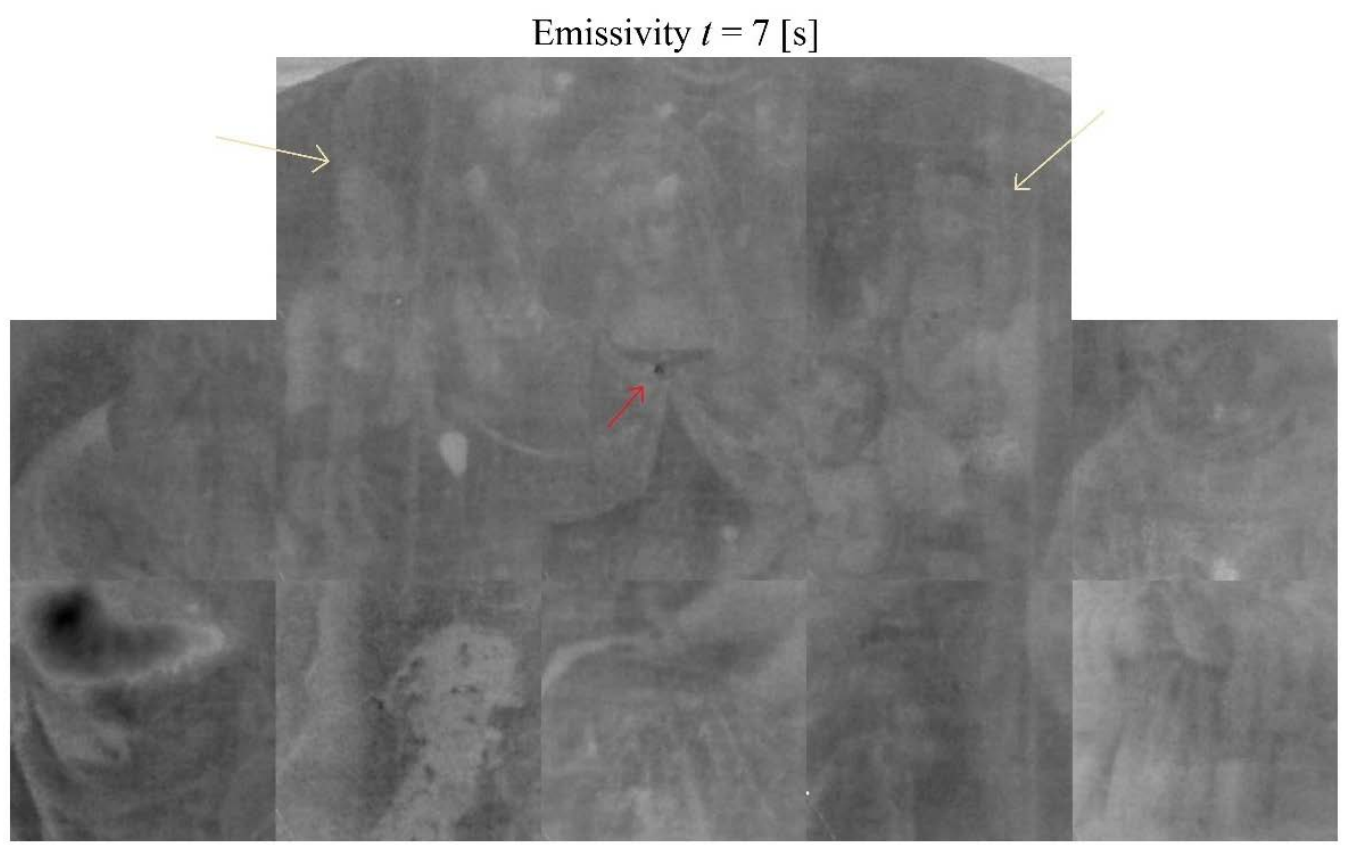

Figure 10. PuCT emissivity image obtained at $t=7 \mathrm{~s}$.

As an example, Fig. 10 depicts the emissivity image at $t=7 \mathrm{~s}$. Signatures of possible deeper

378 detachments/restorations/gluing are visible as vertical contrasted areas, denoted with yellow

379 markers. The texture of the canvas underneath the painting is also barely visible, superimposed to

380 the faint details of the painting scene. An interesting detail concerns the Virgin's cloak closure. In

381 Fig. 9, four lighter-colder spots are clearly visible while in Fig. 10 they are no more present but a

382 darker-hotter spot appeared in the middle of the four previous spots. The evolution of this area in

383 time is illustrated with more details in Fig. 11, where a zoom of this part is reported as time elapses

384 together with the visible image serving as a reference.

385 To better identify the support of the paintings, the images obtained by Hilbert and time-phase

386 features can be used. Indeed, while the emissivity feature is influenced for a quite long time by the

387 temperature rise of the pictorial layer, in the other two features, the details of the pictorial layer, i.e.

388 the painting subject, disappears rapidly and the subsurface layers can be visualized. 


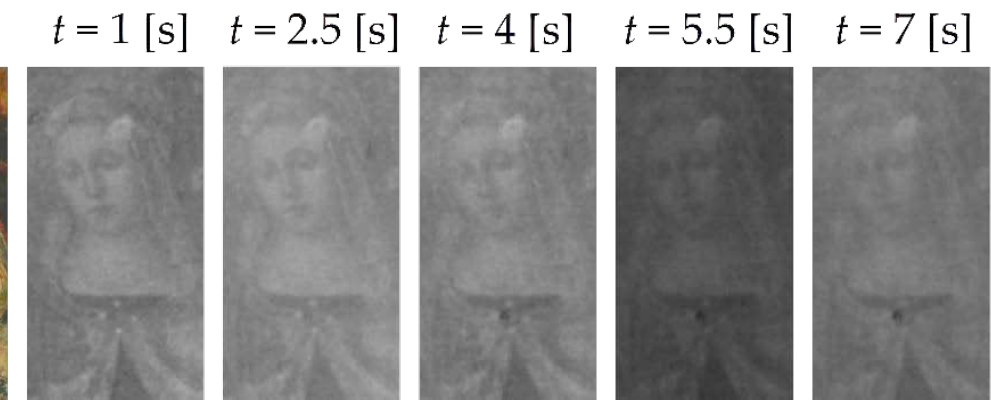

Figure 11. PuCT emissivity images at different times representing Virgin's face and cloak closure. Darker areas corresponds to hotter areas.

392 Figure 12 shows the image of the Hilbert feature at $t=2.5 \mathrm{~s}$, where the canvas texture - including 393 its waviness - is clearly visible. In these thermograms, the following characteristics can be found: (i)

394 a series of cracks, starting from the large retouching at bottom left, passing through the Virgin's

395 knees and Child's feet; (ii) the hot spot of the cloak closure; (iii) the vertical bands and lines present also in Fig. 10; (iv) Saint Jerome's arm that appears darker/hotter; and (v) hot and cold spots scattered all around the painting.

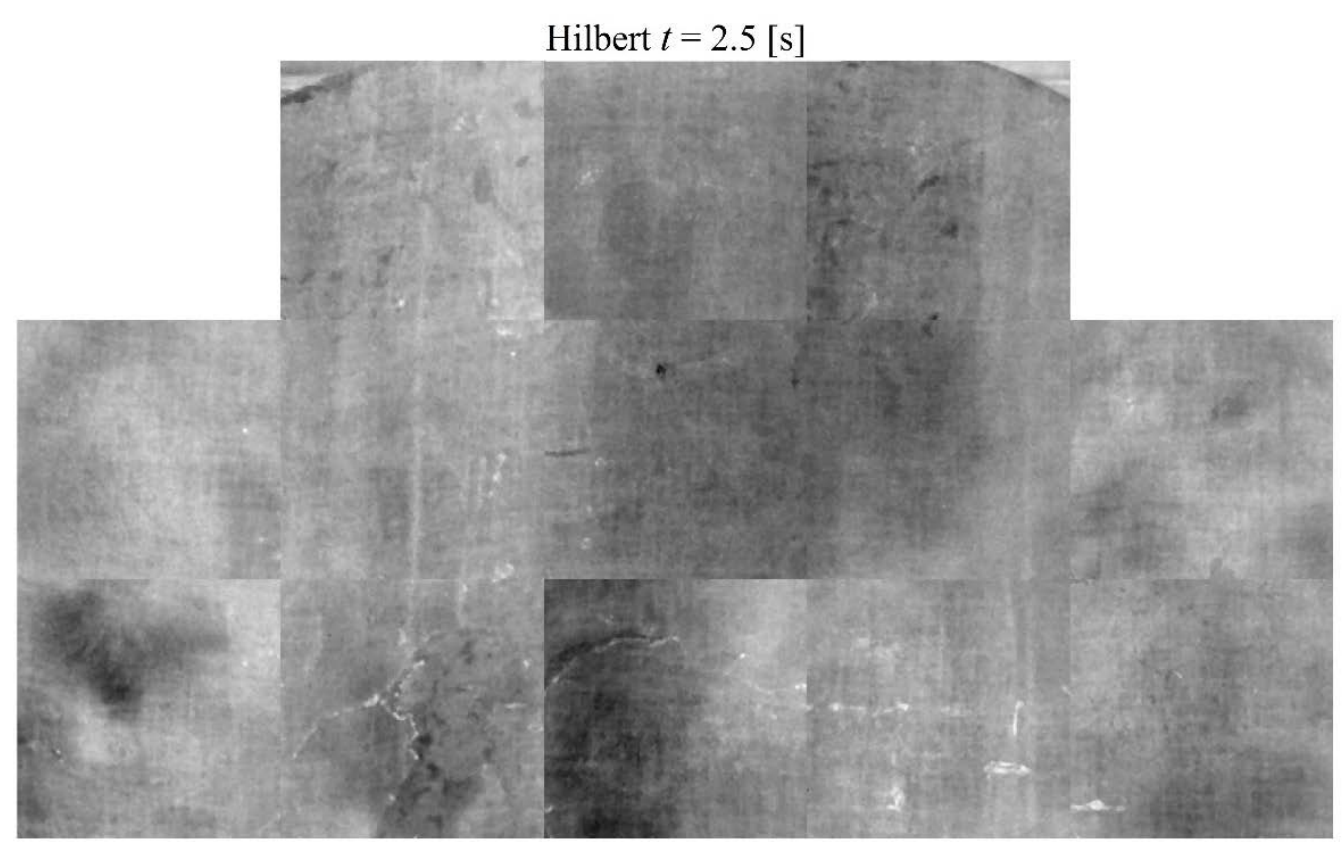

Figure 12. PuCT Hilbert image obtained at $t=2.5 \mathrm{~s}$. 
provide information from the inner structure of the sample to be complemented by HMI information.

PCA can be applied separately to emissivity, Hilbert and time-phase images, or to all the images together. It has been found that the application of PCA to the emissivity time series only allows most of the details of interest to be visualized in a few images, as it can be seen in Figures 13 to 15 showing the first three PCA components. In particular, the PCA3 image in Fig. 15 depicts the canvas under the painting, even if these were not so appreciable in the emissivity images.

As a further investigation, the data reported in Figs. 13-15 have been transformed from the grey scale to the $\mathrm{YCbCr}$ colour space [49]. This is because the human eye have a different perception between a grey scale image and its coloured replica, thus this can help in highlighting areas having different thermal contrasts. Although the perception is inherently highly subjective by nature and further investigation are needed to confirm the validity of the proposed approach - including the possibility to submit a survey to several experts in the field - in our opinion, Figs. 16-18 shows an enhanced perception of the abovementioned area of interests with respect to the same depicted in Figs. 13-15.

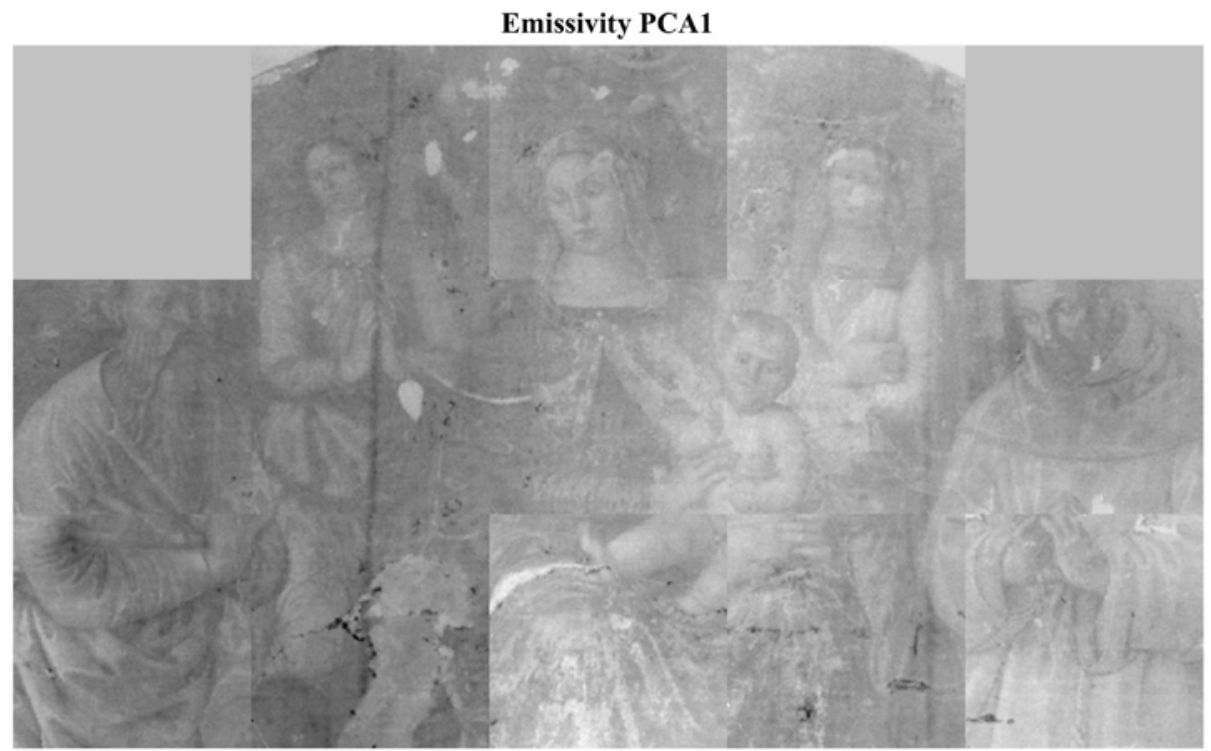




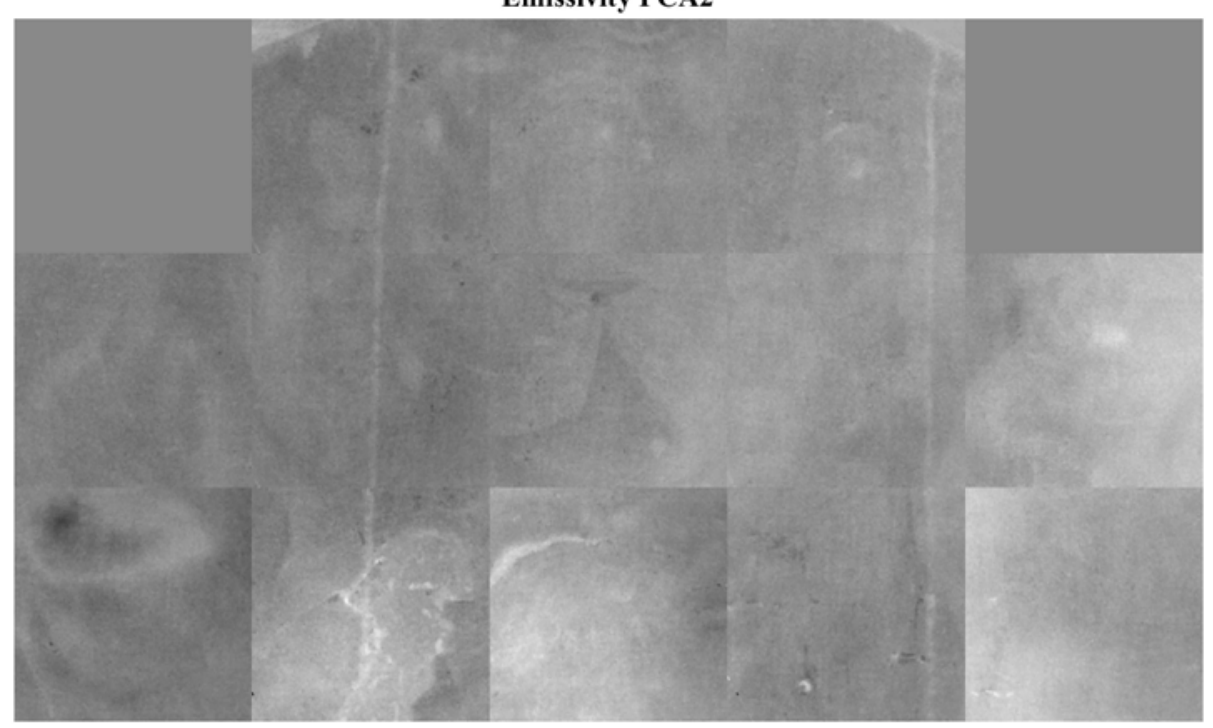

421 Figure 14. Second PCA image retrieved by PuCT emissivity time series image.

Emissivity PCA3

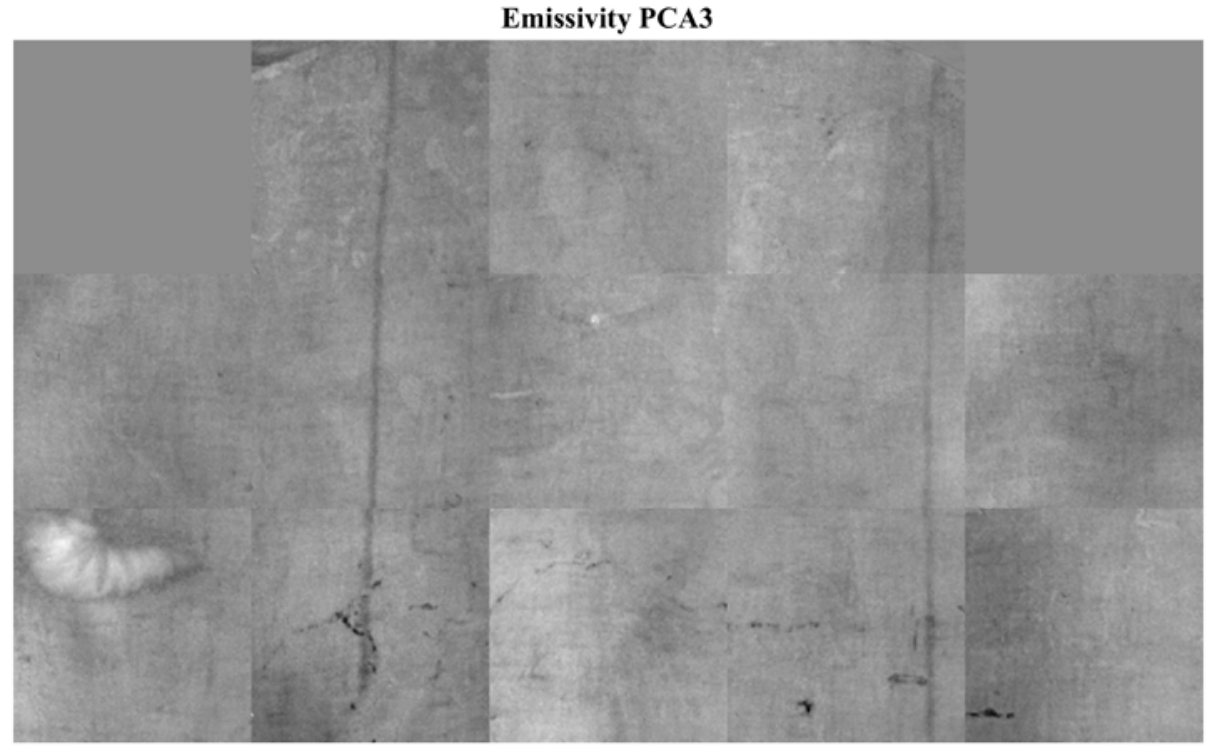

423 Figure 15. Third PCA image retrieved by PuCT emissivity time series image. 


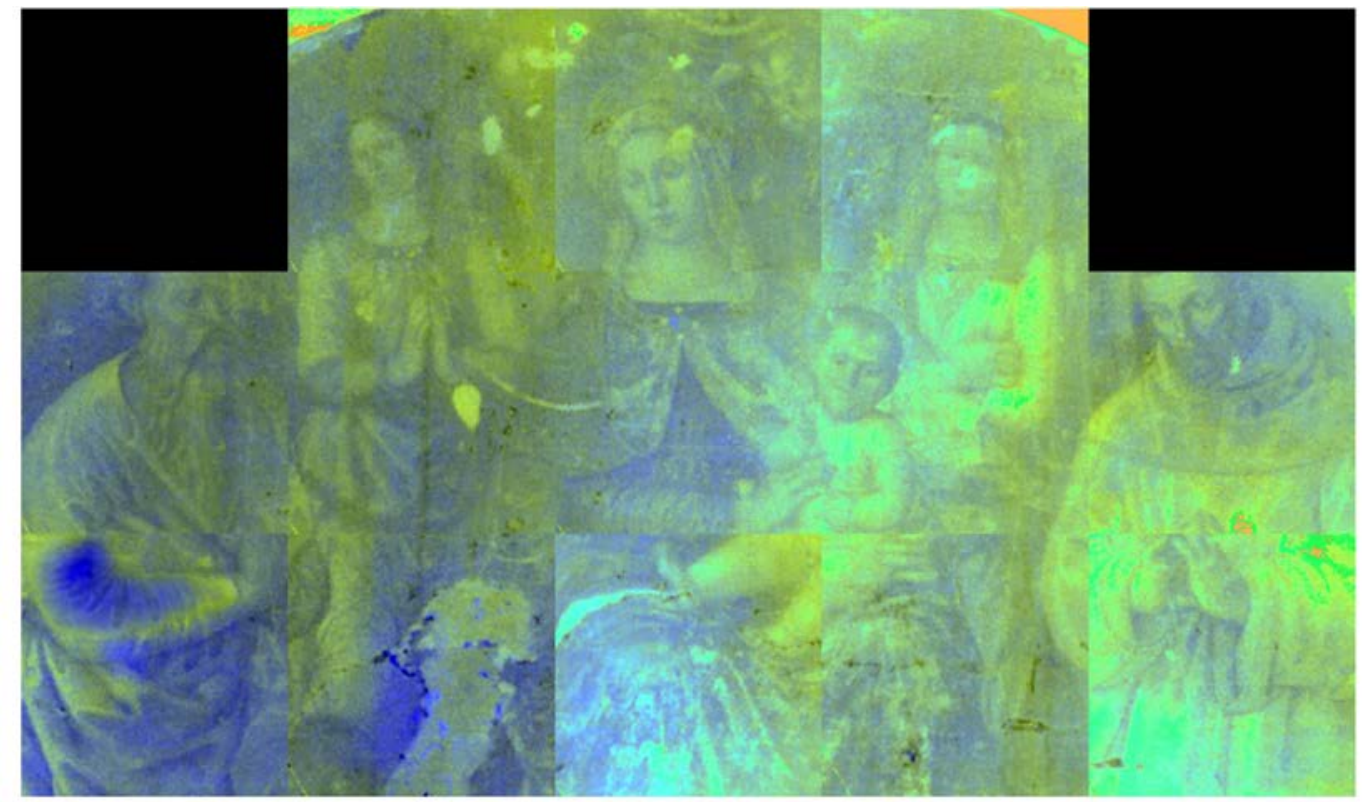

427 Figure 16. False-colour PuCT - YCbCr colour space at $\mathrm{t}=1 \mathrm{~s}$ PCA image retrieved by PuCT emissivity time series image.

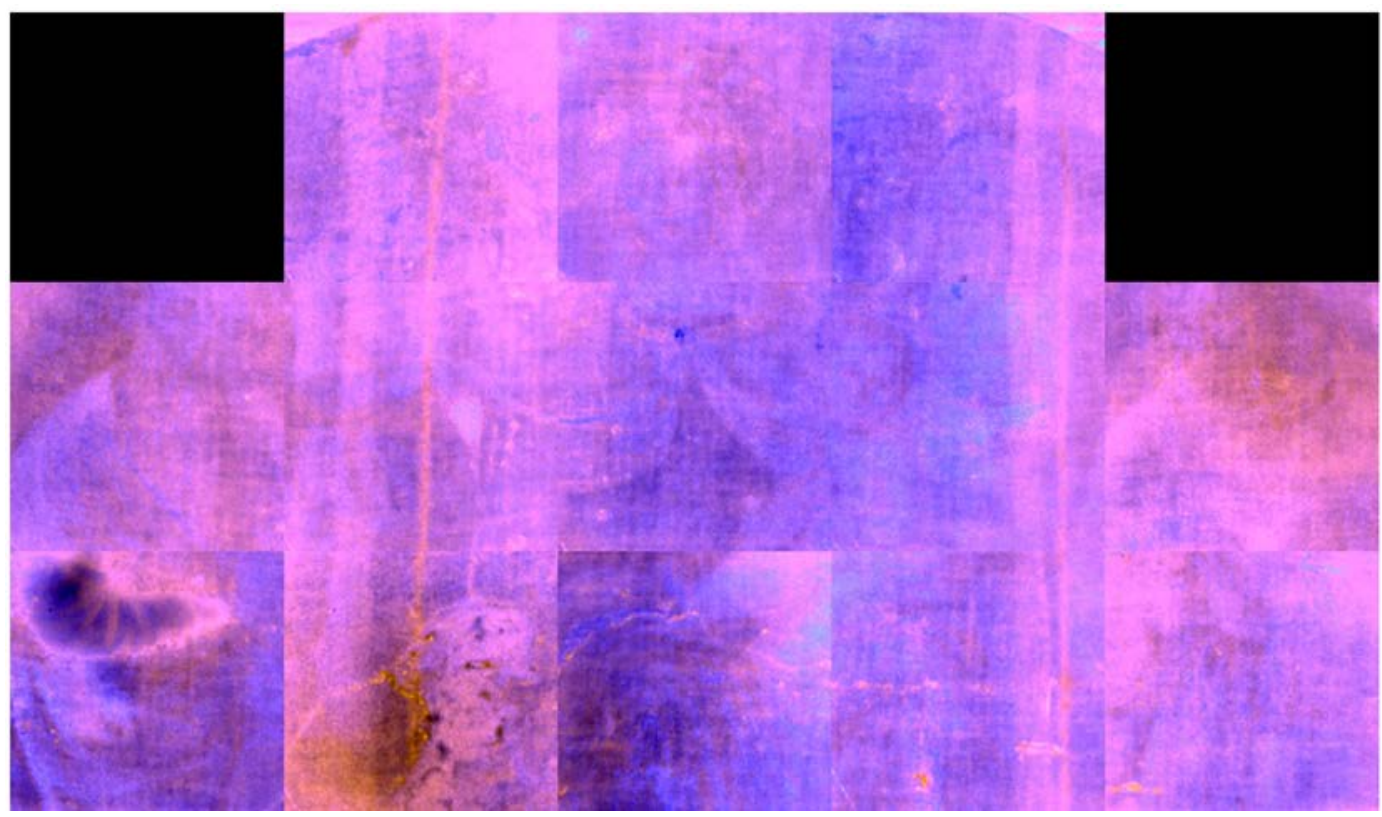
series image. 


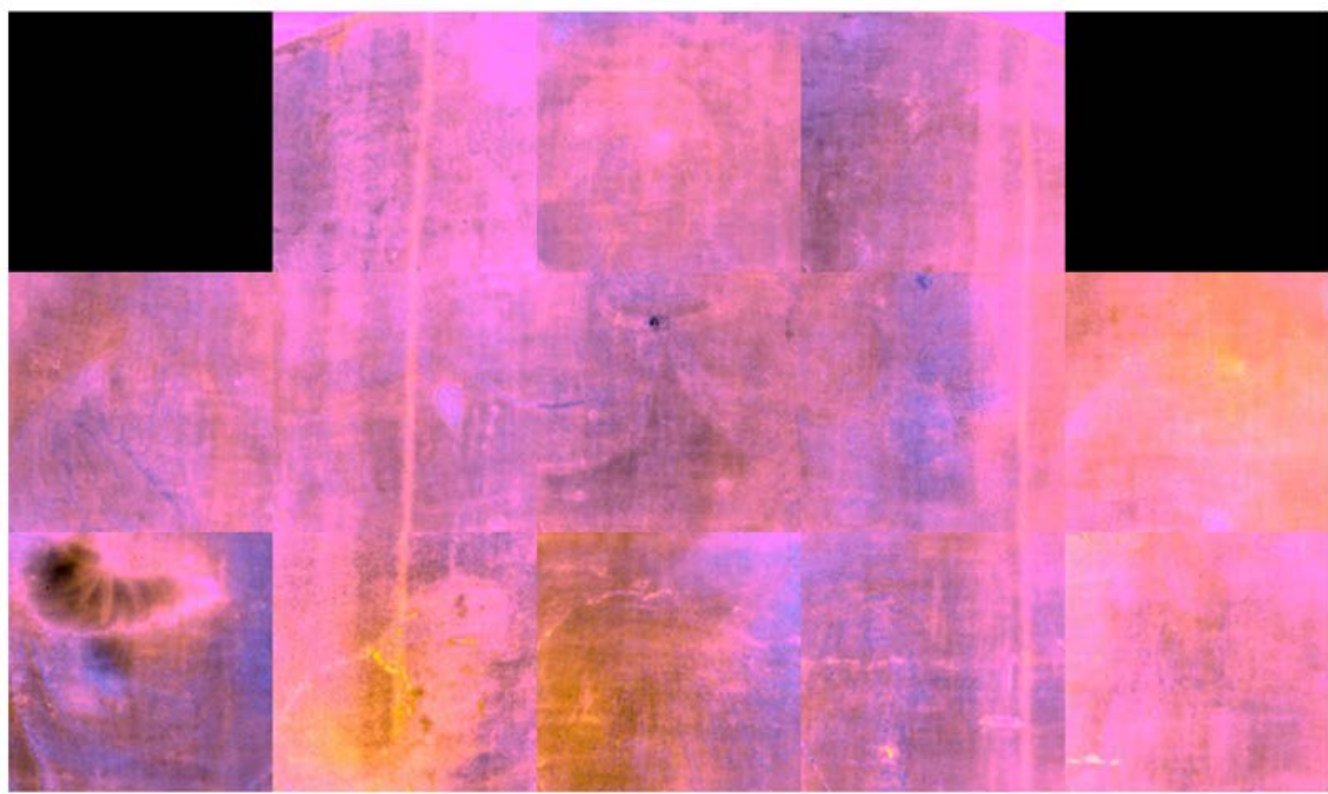

Figure 18. False-colour PuCT $-\mathrm{YCbCr}$ colour space at $\mathrm{t}=4 \mathrm{~s}$ PCA image retrieved by PuCT emissivity time series image.

\section{Conclusions}

Hypercolorimetric Multispectral Imaging (HMI) and Pulse-Compression Thermography

$(\mathrm{PuCT})$ have been tested on a detached wall painting representing the Madonna and the Child enthroned between the angels and the Saints Jerome and Francis (AD 1490), attributed to the painter Antonio del Massaro known as Pastura (1450-1519).

The combined use of the two techniques, for the first time on a wall painting, was possible thanks to the restoration work, offering the chance for investigating the artwork to study the materials, the construction techniques, the state of preservation and the stratigraphic pattern as consequence of the detachment operations performed at the beginning of the $20^{\text {th }}$ century. pigment composition and distribution, and preparatory drawing/pentimenti, respectively.

PuCT output signatures of detachments, grouting, gilding from the surface to the deep layers 448 giving relevant information about the possible presence of discontinuity or deep grouts. A color space transformation from gray scale to $\mathrm{YCbCr}$ was found to be useful for highlighting areas of interest. 
Further processing of the acquired images will be possible also with the support of conservators

\section{Declarations}

454 Availability of Data and Material: The datasets used and/or analysed during the current study are available

455 from the corresponding author on reasonable request.

456 Competing Interest: The authors declare no competing of interest.

457 Funding: This research received no external funding

458 Author Contributions: Conceptualization, M.R., M.M., S.S., S.L, G.C. and C.P.; methodology, M.R., S.S., M.M.,

C.P. and S.L.; software, S.L., M.R., M.M..; validation, S.L., M.R., M.M. and H.M; formal analysis, S.L., M.R., G.A.,

L.L., C.C. and H.M; investigation, M.R., S.L., G.A., L.L., C.C. and H.M; resources, G.C., M.R., S.S. and C.P.; data curation, M.R., C.P., S.L., C.C. and H.M; writing-original draft preparation, C.P. and M.R.; writing-review and editing, S.L. and H.M; visualization, C.C., M.R., G.A., L.L. and S.L.; supervision, G.C. and M.R.; project to the published version of the manuscript. authors acknowledge fruitful discussions with Dr. Saverio Ricci about the history of the artwork inspected.

\section{List of abbreviations:}

$\begin{array}{ll}\text { HMI } & \text { Hypecolorimetric multispectral imaging } \\ \text { PuCT } & \text { Pulse-compression thermography } \\ \text { CH } & \text { Cultural heritage } \\ \text { MS } & \text { Multispectral } \\ \text { HS } & \text { Hyperspectral } \\ \text { UV } & \text { Ultraviolet } \\ \text { VIS } & \text { Visible } \\ \text { IR } & \text { Infrared } \\ \text { TTR } & \text { Terahertz time resolved } \\ \text { OCT } & \text { Optical coherence tomography } \\ \text { IRT } & \text { Infrared thermography } \\ \text { UVF } & \text { Ultraviolet fluorescence } \\ \text { LED } & \text { Light emitting diode } \\ \text { AWG } & \text { Arbitrary waveform generator } \\ \text { PCA } & \text { Principal component analysis } \\ \text { SNR } & \text { Signal-to-noise ratio }\end{array}$


PuC Pulse-compression

GUI Graphical user interface

IRFC Infrared false colour

\section{References}

1. Aldrovandi A, Bertani D, Cetica M, Matteini M, Moles A, Poggi P, Tiano P. Multispectral image processing of paintings. Studies in Conservation. 1988 Aug 1;33(3):154-9.

2. Mairinger F. UV-, IR-and X-ray imaging. Non-destructive microanalysis of cultural heritage materials. 2004 Jan 1;42:15-73.

3. Saunders D, Billinge R, Cupitt J, Atkinson N, Liang H. A new camera for high-resolution infrared imaging of works of art. Studies in conservation. 2006 Jan 1;51(4):277-90.

4. Fischer C, Kakoulli I. Multispectral and hyperspectral imaging technologies in conservation: current research and potential applications. Studies in Conservation. 2006 Jun 1;51(sup1):3-16.

5. Kubik M. Hyperspectral imaging: a new technique for the non-invasive study of artworks. Physical techniques in the study of art, archaeology and cultural heritage. 2007 Jan 1;2:199-259.

6. Delaney JK, Zeibel JG, Thoury M, Littleton RO, Palmer M, Morales KM, de La Rie ER, Hoenigswald AN. Visible and infrared imaging spectroscopy of Picasso's Harlequin musician: mapping and identification of artist materials in situ. Applied spectroscopy. 2010 Jun 1;64(6):584-94.

7. Adam AJ, Planken PC, Meloni S, Dik J. Terahertz imaging of hidden paint layers on canvas. Optics Express. 2009 Mar 2;17(5):3407-16.

8. Fukunaga K, Picollo M. Terahertz spectroscopy applied to the analysis of artists' materials. Applied Physics A. 2010 Sep 1;100(3):591-7.

9. Casini A, Bacci M, Cucci C, Lotti F, Porcinai S, Picollo M, Radicati B, Poggesi M, Stefani L. Fiber optic reflectance spectroscopy and hyper-spectral image spectroscopy: two integrated techniques for the study of the Madonna dei Fusi. In Optical methods for arts and archaeology 2005 Aug 12 (Vol. 5857, p. 58570M). International Society for Optics and Photonics.

10. Elias M, Mas N, Cotte P. Review of several optical non-destructive analyses of an easel painting. Complementarity and crosschecking of the results. Journal of cultural heritage. 2011 Oct 1;12(4):335-45.

11. Luciani G, Pelosi C, Agresti G, Lo Monaco A. How to reveal the invisible the fundamental role of diagnostics for religious painting investigation. Eur. J. Sci. Theol. 2019 Jun;15:209-20. 
12. Lanteri L, Agresti G, Pelosi C. A new practical approach for 3D documentation in ultraviolet fluorescence and infrared reflectography of polychromatic sculptures as fundamental step in restoration. Heritage. 2019 Mar;2(1):207-15.

13. Colantonio C, Pelosi C, D'Alessandro L, Sottile S, Calabrò G, Melis M. Hypercolorimetric multispectral imaging system for cultural heritage diagnostics: an innovative study for copper painting examination. The European Physical Journal Plus. 2018 Dec 1;133(12):526.

14. Pelosi C, Calienno L, Fodaro D, Borrelli E, Rubino AR, Sforzini L, Lo Monaco A. An integrated approach to the conservation of a wooden sculpture representing Saint Joseph by the workshop of Ignaz Günther (1727-1775): analysis, laser cleaning and 3D documentation. Journal of Cultural Heritage. 2016 Jan 1;17:114-22

15. Lo Monaco A, Giagnacovo C, Falcucci C, Pelosi C. The triptych of the Holy Saviour in the Tivoli Cathedral: diagnosis, conservation and religious requirements. European Journal of Science and Theology. 2015 Apr $1 ; 11(2): 241-52$.

16. Pelosi C, Falcucci C, Ardagna V. Investigation of a medieval illuminated manuscript through non-invasive techniques. European Journal of Science and Theology. 2017 Apr 1;13(2):61-8.

17. Laureti S, Malekmohammadi H, Rizwan MK, Burrascano P, Sfarra S, Mostacci M, Ricci M. Looking through paintings by combining hyper-spectral imaging and pulse-compression thermography. Sensors. 2019 Jan;19(19):4335.

18. Rosi F, Miliani C, Braun R, Harig R, Sali D, Brunetti BG, Sgamellotti A, Noninvasive analysis of paintings by mid-infrared hyperspectral imaging. Angewante Chemie 2013; 52:1-5.

19. Melis M, Miccoli M, Quarta D. Multispectral hypercolorimetry and automatic guided pigment identification: some masterpieces case studies. In Optics for arts, architecture, and archaeology IV 2013 May 30 (Vol. 8790, p. 87900W). International Society for Optics and Photonics.

20. Samadelli M, Melis M, Miccoli M, Vigl EE, Zink AR. Complete mapping of the tattoos of the 5300-year-old Tyrolean Iceman. Journal of Cultural Heritage. 2015 Sep 1;16(5):753-8.

21. Melis M, Miccoli M. Trasformazione evoluzionistica di una fotocamera reflex digitale in un sofisticato strumento per misure fotometriche e colorimetriche. Proc. Colore e Colorimetria contributi multidisciplinari; RN, Italy, 2013; Vol. IXA, pp. 28-38. 
22. Dong J, Locquet A, Melis M, Citrin DS. Global mapping of stratigraphy of an old-master painting using sparsity-based terahertz reflectometry. Scientific reports. 2017 Nov 8;7(1):1-2.

23. Alberghina MF, Macchia A, Capizzi P, Schiavone S, Ruffolo SA, Comite V, Barberio M, La Russa MF. Surface and volume non-invasive methods for the structural monitoring of the bass-relief 'Madonna con Bambino'(Gorizia, Northern Italy). Natural product research. 2019 Apr 3;33(7):1034-9.

24. Elkhuizen WS, Callewaert TW, Leonhardt E, Vandivere A, Song Y, Pont SC, Geraedts JM, Dik J. Comparison of three 3D scanning techniques for paintings, as applied to Vermeer's 'Girl with a Pearl Earring'. Heritage Science. 2019 Dec 1;7(1):89.

25. Zhang H, Sfarra S, Saluja K, Peeters J, Fleuret J, Duan Y, Fernandes H, Avdelidis N, Ibarra-Castanedo C, Maldague X. Non-destructive investigation of paintings on canvas by continuous wave terahertz imaging and flash thermography. Journal of Nondestructive Evaluation. 2017 Jun 1;36(2):34.

26. Maldague X. Theory and practice of infrared thermography for nondestructive testing. Wiley series in microwave and optical engineering. Wiley: Hoboken NJ, USA, 2001.

27. Bodnar JL, Nicolas JL, Candoré JC, Detalle V. Non-destructive testing by infrared thermography under random excitation and ARMA analysis. International Journal of Thermophysics. 2012 Nov 1;33(10-11):2011-5.

28. Silipigni G, Burrascano P, Hutchins DA, Laureti S, Petrucci R, Senni L, Torre L, Ricci M. Optimization of the pulse-compression technique applied to the infrared thermography nondestructive evaluation. NDT \& E International. 2017 Apr 1;87:100-10.

29. Laureti S, Sfarra S, Malekmohammadi H, Burrascano P, Hutchins DA, Senni L, Silipigni G, Maldague XP, Ricci M. The use of pulse-compression thermography for detecting defects in paintings. Ndt \& E International. 2018 Sep 1;98:147-54.

30. Sfarra S, Laureti S, Gargiulo G, Malekmohammadi H, Sangiovanni MA, La Russa M, Burrascano P, Ricci M. Low Thermal Conductivity Materials and Very Low Heat Power: A Demanding Challenge in the Detection of Flaws in Multi-Layer Wooden Cultural Heritage Objects Solved by Pulse-Compression Thermography Technique. Applied Sciences. 2020 Jan;10(12):4233.

31. Laureti S, Colantonio C, Burrascano P, Melis M, Calabrò G, Malekmohammadi H, Sfarra S, Ricci M, Pelosi C. Development of integrated innovative techniques for paintings examination: The case studies of The 

Resurrection of Christ attributed to Andrea Mantegna and the Crucifixion of Viterbo attributed to Michelangelo's workshop. Journal of Cultural Heritage. 2019 Nov 1;40:1-6.

32. Gittins M, Agresti G, Catalano MI, Pelosi C, Pogliani P. La lunette raffigurante Madonna con Bambino in trono tra gli angeli e i Santi Francesco e Girolamo staccato dal convento di Santa Maria del Paradiso per il Museo Civico di Viterbo: fortuna dell'opera e storia conservativa alla luce dell'ultimo restauro (2016-2017). In Proc. XV Congresso Nazionale IGIIC Lo Stato dell'Arte. Firenze, Italy, 2017; pp. 461-468.

33. Ricci C. Antonio da Viterbo detto il Pastura e l'Appartamento Borgia. Per l'inaugurazione del Museo Civico di Viterbo. Agnesotti: Viterbo, Italy, 1912; pp. 23-27.

34. Zuccari A. L'attività viterbese di Antonio del Massaro detto il Pastura. Il Quattrocento a Viterbo. Milano, 1983; pp. 222-239.

35. Rinaldi S. I dipinti del Museo Civico di Viterbo. Censimento conservativo in omaggio a Michele Cordaro. Ediart: Tody, Italy, 2004; p. 75.

36. Pelosi C, Lanteri L, Agresti G, Santamaria U. Documentation and Scientific Investigation on the "Crucifixion" by Balletta in the church of Santa Maria Nova in Viterbo (Italy). Conservation and Religious Requirements. European Journal of Science and Theology. 2016 Feb;12(1):271-81.

37. Lanteri L, Agresti G. Ultraviolet fluorescence 3D models for diagnostics of cultural heritage. Eur. J. Sci. Theol. 2017 Apr 1;13:35-40.

38. Derrick MR, Stulik D, Landry JM. Infrared spectroscopy in conservation science. Getty Publications; 2000 Mar 16.

39. Meilunas RJ, Bentsen JG, Steinberg A. Analysis of aged paint binders by FTIR spectroscopy. Studies in conservation. 1990 Feb 1;35(1):33-51.

40. Bro R, Smilde AK. Principal component analysis. Analytical Methods. 2014;6(9):2812-31.

41. Pelosi C, Capobianco G, Agresti G, Bonifazi G, Morresi F, Rossi S, Santamaria U, Serranti S. A methodological approach to study the stability of selected watercolours for painting reintegration, through reflectance spectrophotometry, Fourier transform infrared spectroscopy and hyperspectral imaging. Spectrochimica Acta Part A: Molecular and Biomolecular Spectroscopy. 2018 Jun 5;198:92-106.

42. Lau D, Villis C, Furman S, Livett M. Multispectral and hyperspectral image analysis of elemental and micro-Raman maps of cross-sections from a 16th century painting. Analytica chimica acta. 2008 Mar $3 ; 610(1): 15-24$. 
581 43. Cosentino A. Infrared technical photography for art examination. e-Preservation Science. 2016;13:1-6.

582 44. Cosentino A. Identification of pigments by multispectral imaging; a flowchart method. Heritage Science. $2014 \operatorname{Dec} 1 ; 2(1): 8$

584 45. Cosentino A. Effects of different binderson technical photography and reflectrography of 54 historical 585 pigments. International Journal of Conservation Science. 2015 Sep 1;6(3).

586 46. Cavallo G. Alteration of azurite into paratacamite at the St. Alessandro church (Lasnigo, Italy). Conservar património. 2009(9):5-11.

588 47. Sandu IC, Afonso LU, Murta E, de Sa MH. Gilding techniques in religious art between east and west, 14th-18th centuries. International Journal of Conservation Science. 2010 Mar;1(1):47-62.

48. Sandu IC, Afonso LU, Murta E, de Sa MH. Gilding techniques in religious art between east and west, 14th-18th centuries. International Journal of Conservation Science. 2010 Mar;1(1):47-62.

592 49. Liu C, van Netten JJ., Van Baal JG, Bus SA, van Der Heijden F. Automatic detection of diabetic foot complications with infrared thermography by asymmetric analysis. Journal of biomedical optics. $2015 ; 20(2), 026003$.

(C) 2020 by the authors. Submitted for possible open access publication under the terms and conditions of the Creative Commons Attribution (CC BY) license (http://creativecommons.org/licenses/by/4.0/). 


\section{Figures}

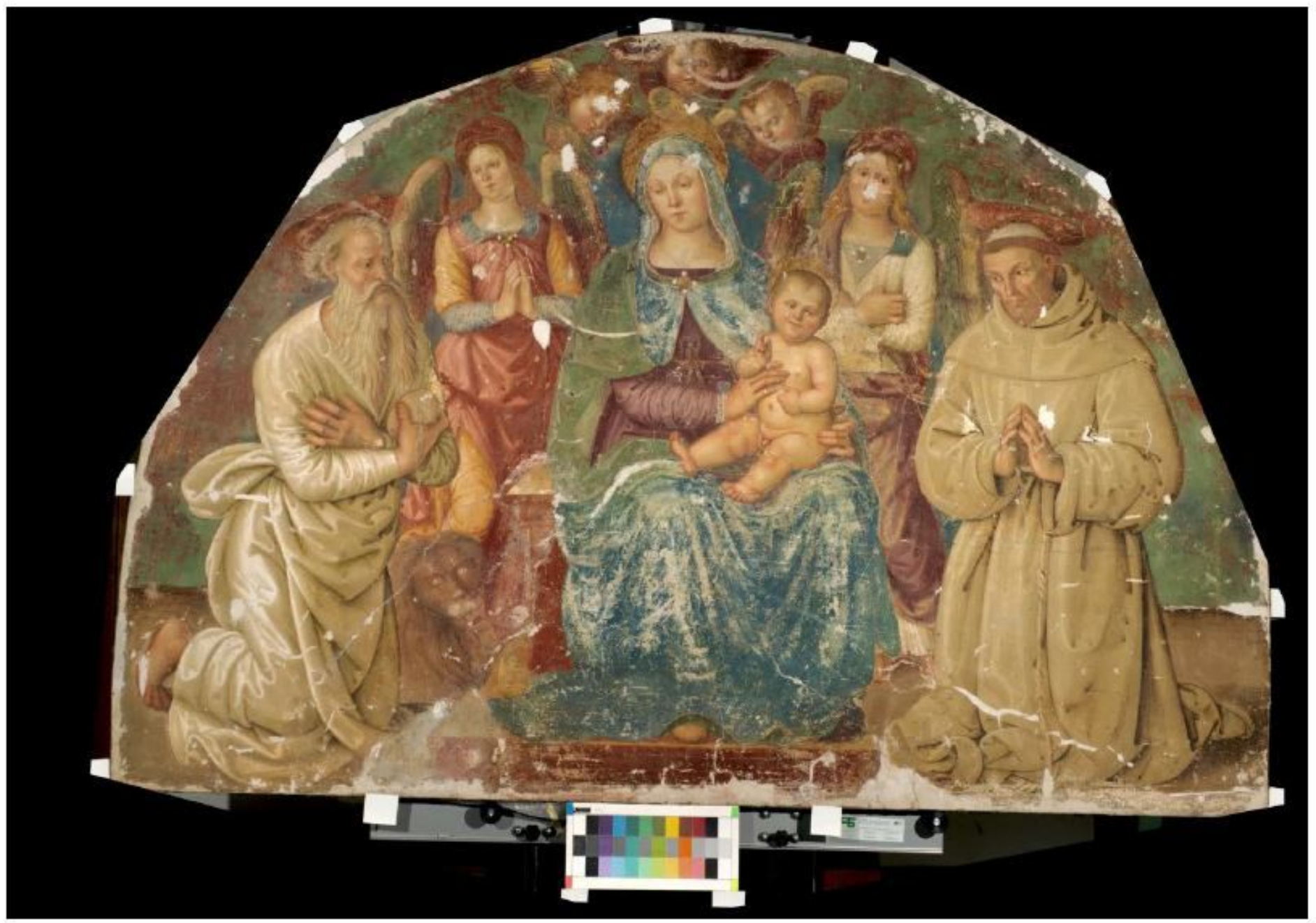

\section{Figure 1}

The lunette with Madonna and the Child enthroned between the angels and the Saints Jerome and Francis (AD 1490), attributed to the painter Antonio del Massaro known as Pastura (1450-1519). The calibrated visible image with the colour checker and the white patches used for HMI acquisition is shown in the figure. 


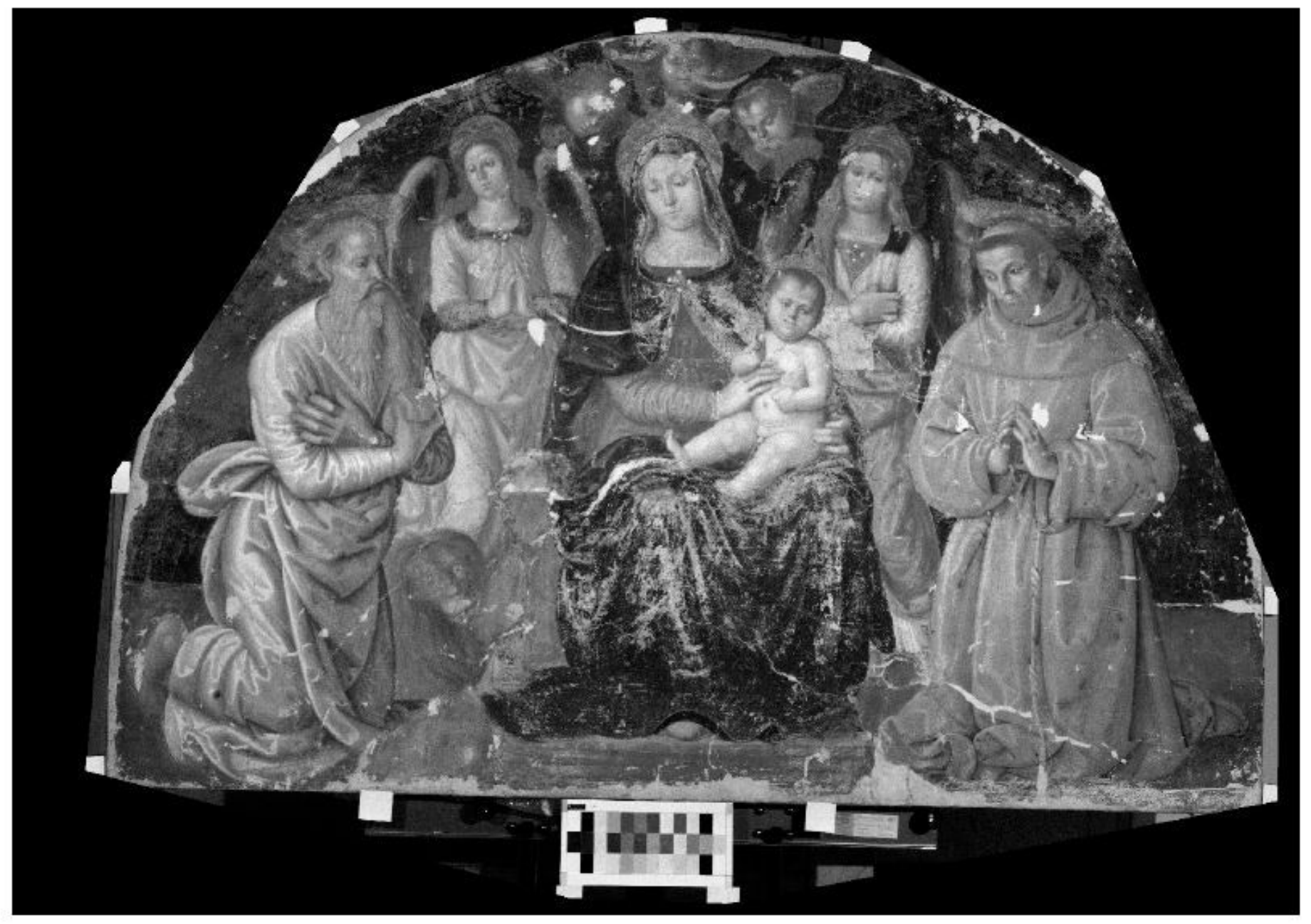

Figure 2

The HMI infrared calibrated image at $850 \mathrm{~nm}$ (IR2) showing the preparatory drawing used for the construction of the painting. 


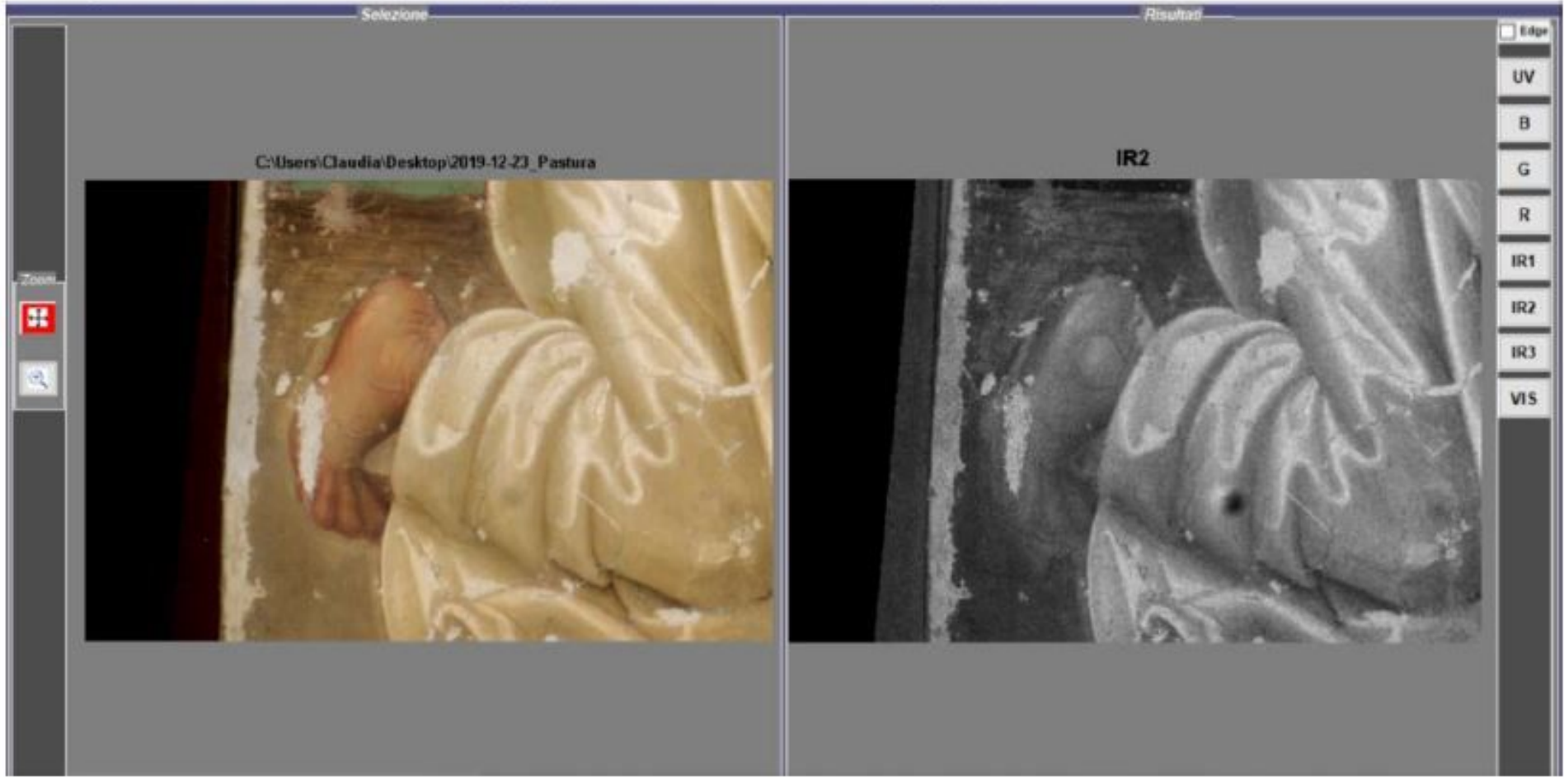

Figure 3

A detail of the $\mathrm{HMI}$ infrared calibrated image at $850 \mathrm{~nm}$ (IR2) showing the pentimento in the drawing of Saint Jerome foot.

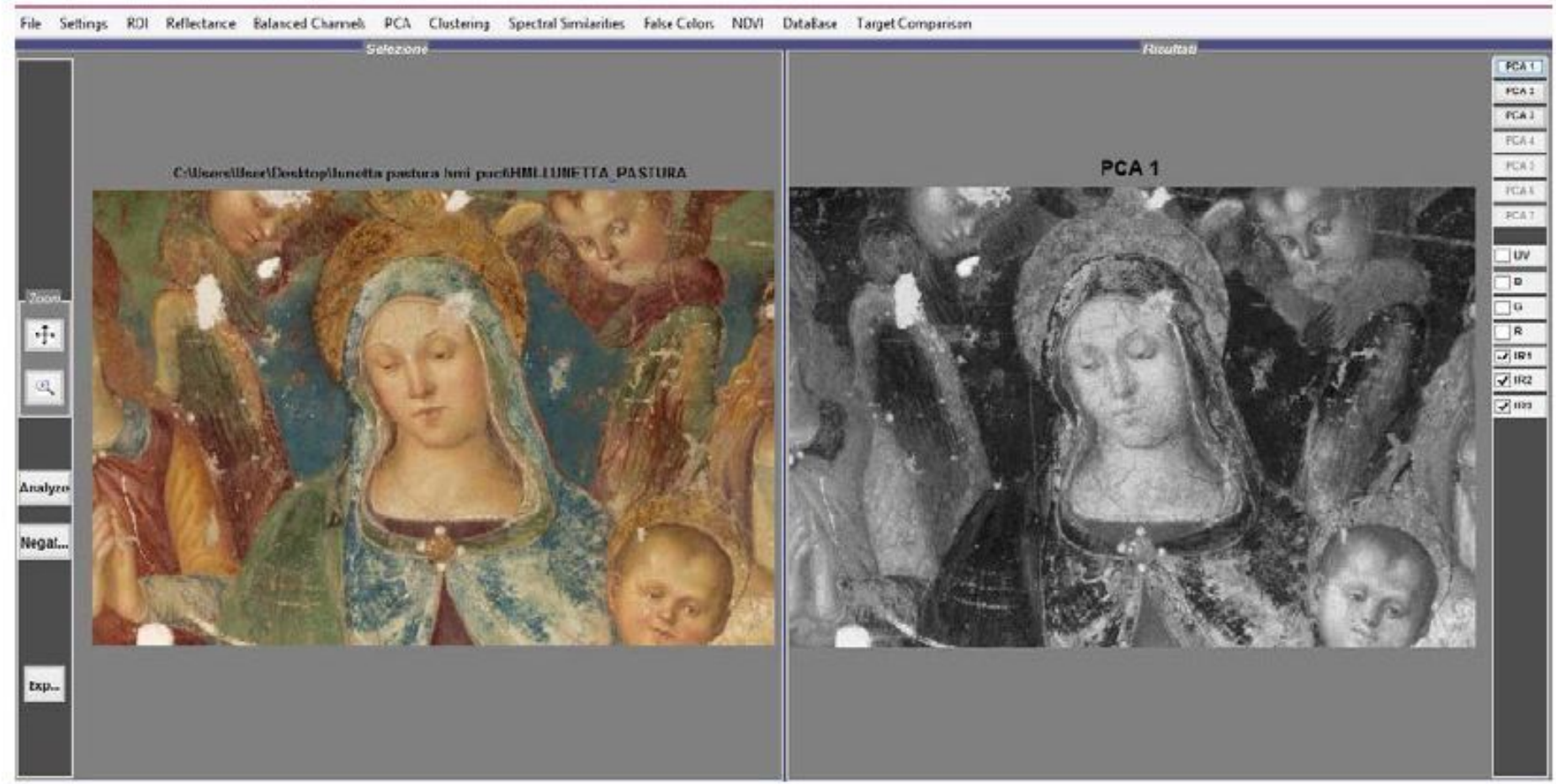

Figure 4 
PCA applied to IR1-IR2-IR3 calibrated images showing an extensive cracking in correspondence of the Virgin's face and neck.

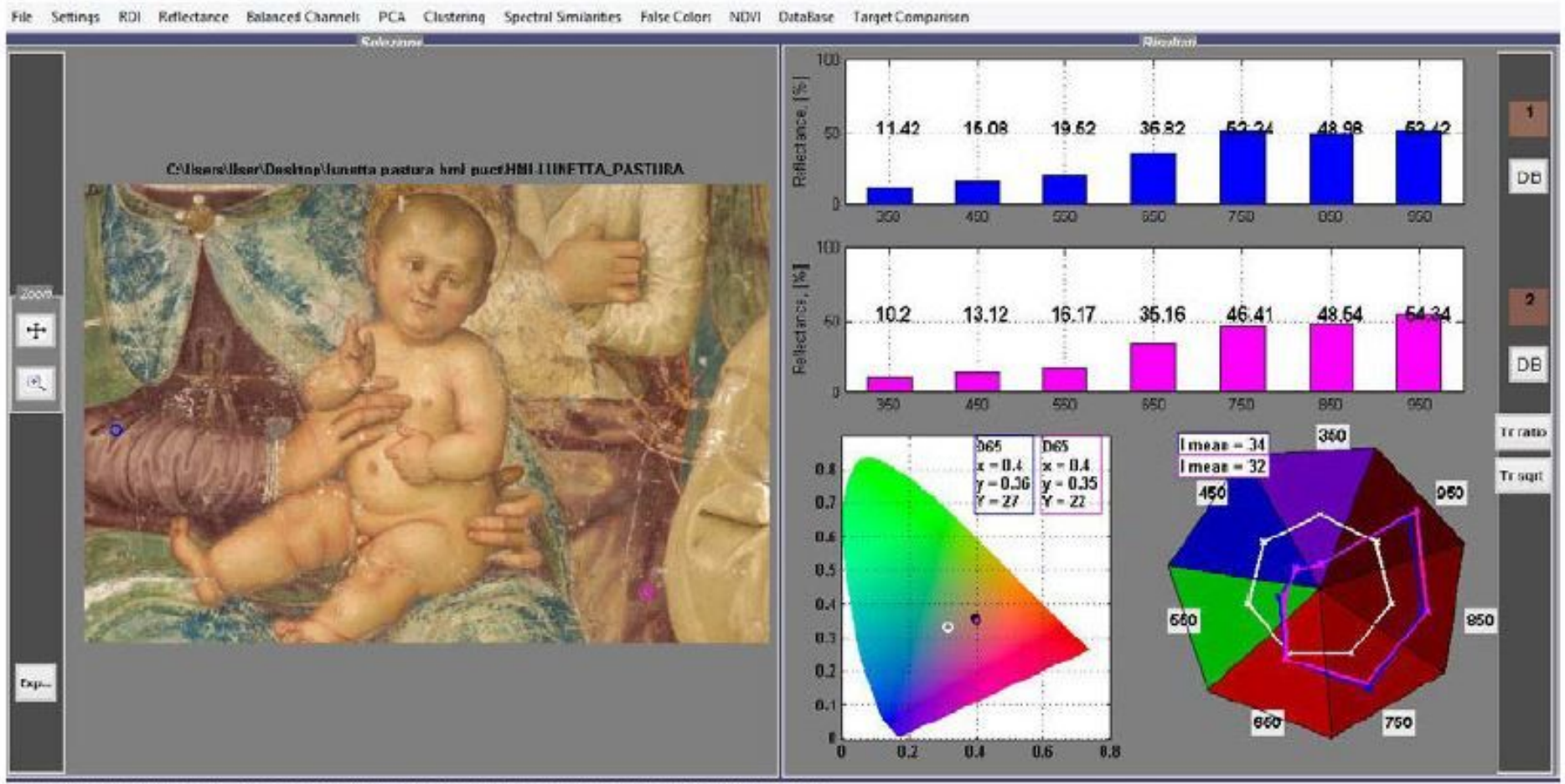

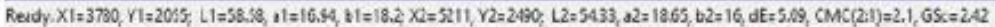

\section{Figure 5}

Spectral Similarities tool applied to a point on the arm of the Virgin garment and on the Angel's dress. High similarity is found both in terms of reflectance values and of colour coordinates. 


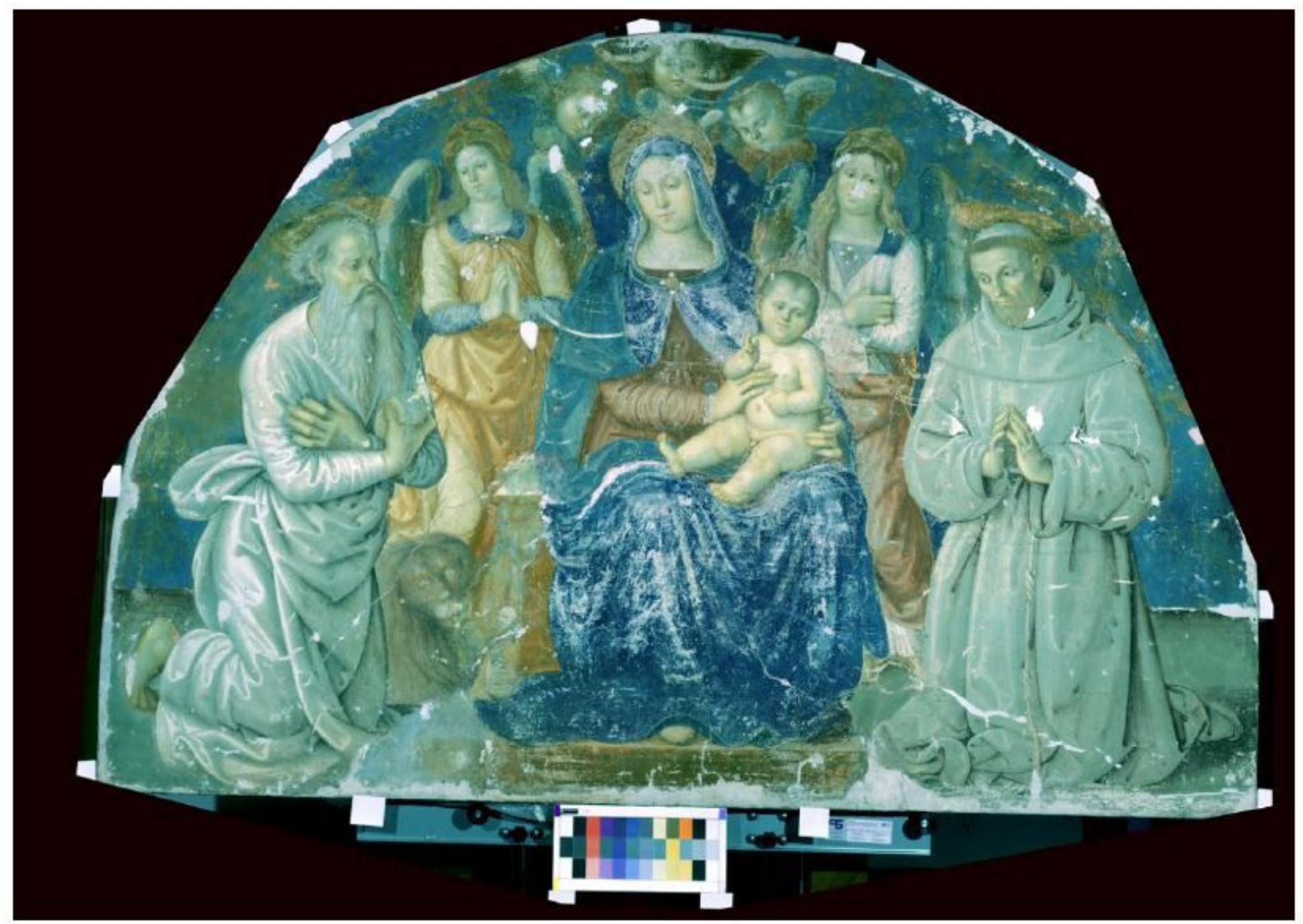

Figure 6

Infrared false colour image obtained through PickViewer ${ }^{\circledR}$. 


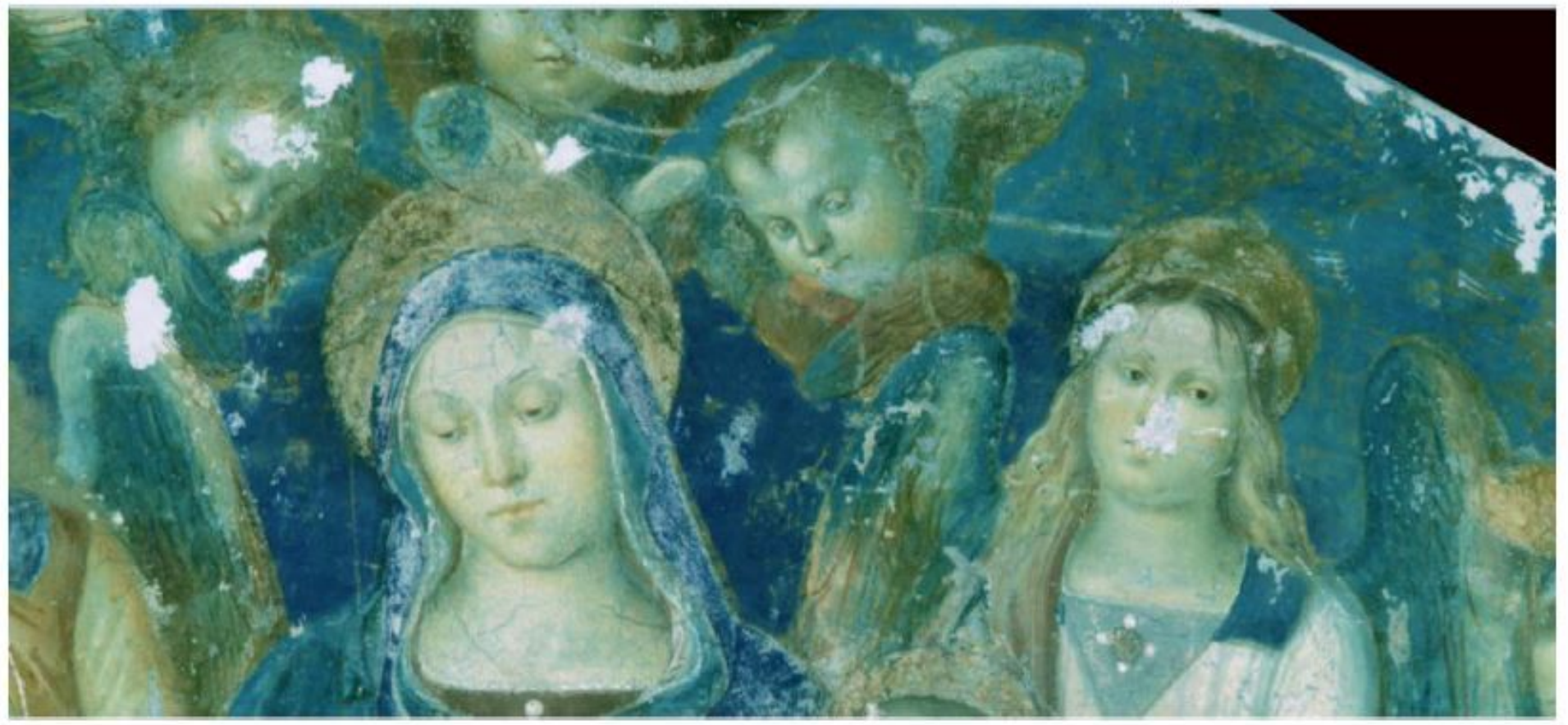

\section{Figure 7}

Detail of IRFC image showing the blue portion of the probable unaltered azurite in the background sky behind the head of the Virgin.

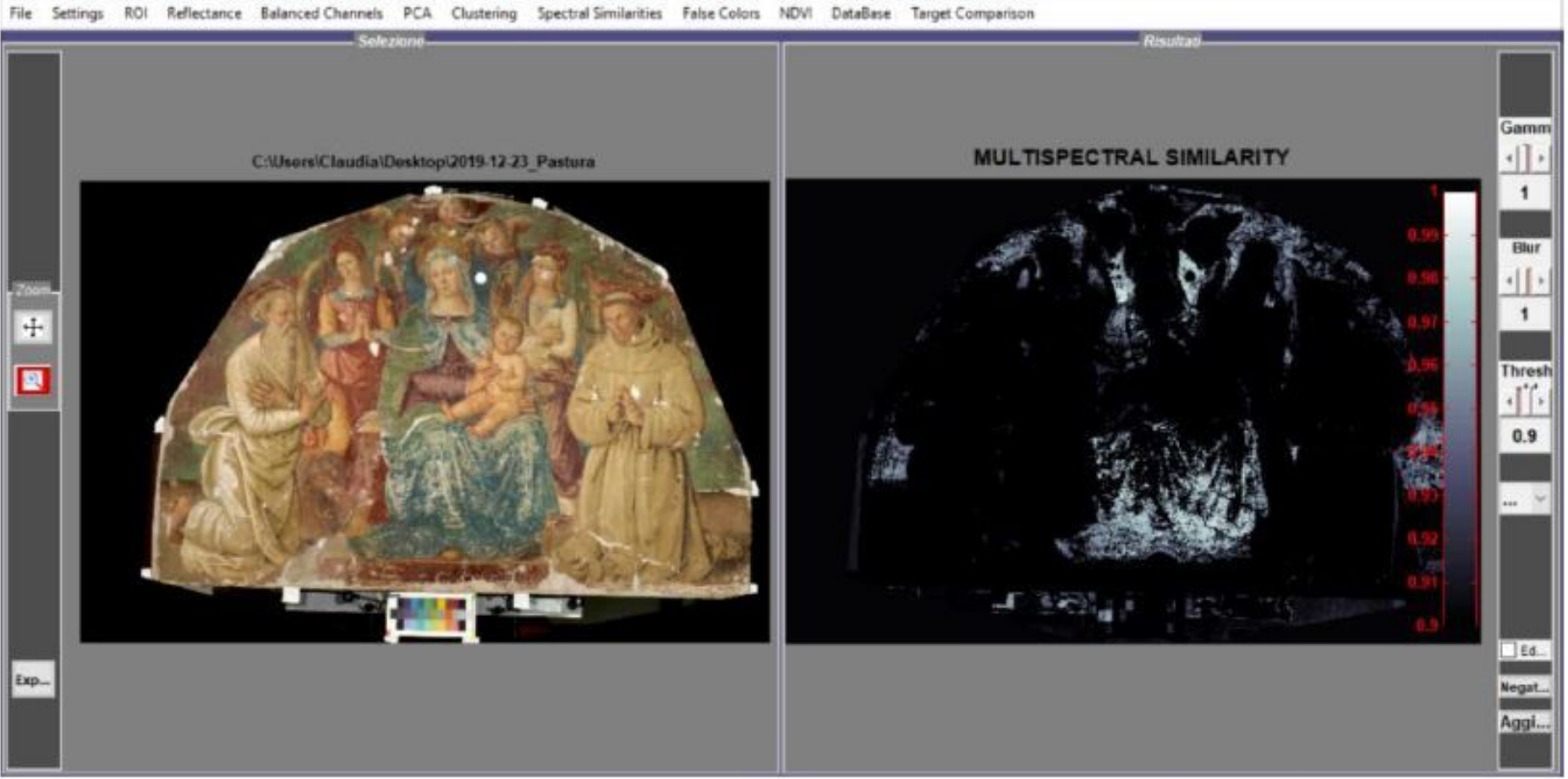

\section{Figure 8}

Multispectral similarity mapping of azurite. 


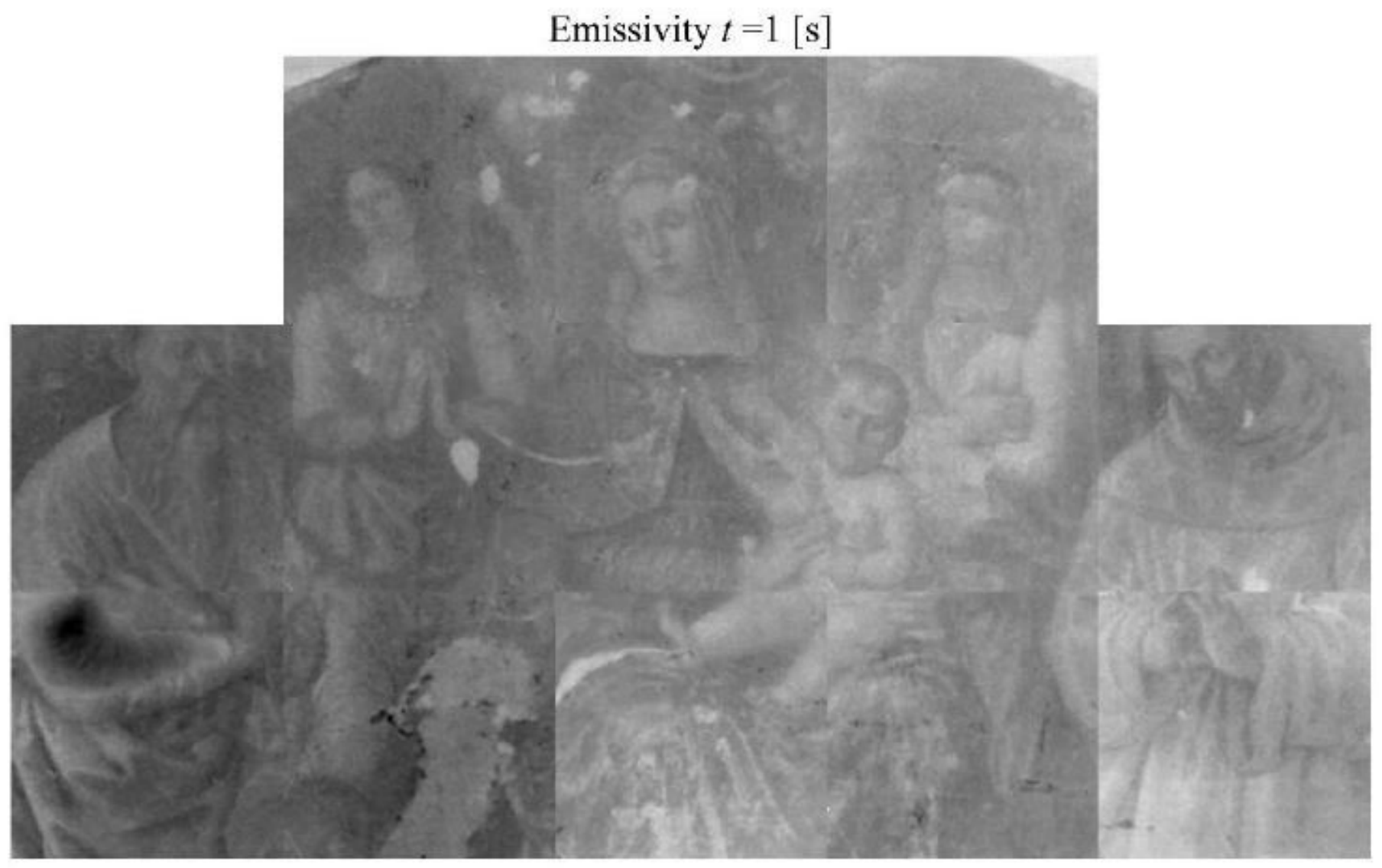

Figure 9

PuCT emissivity image obtained at $\bigotimes=1 \mathrm{~s}$. 


\section{Emissivity $t=7[\mathrm{~s}]$}

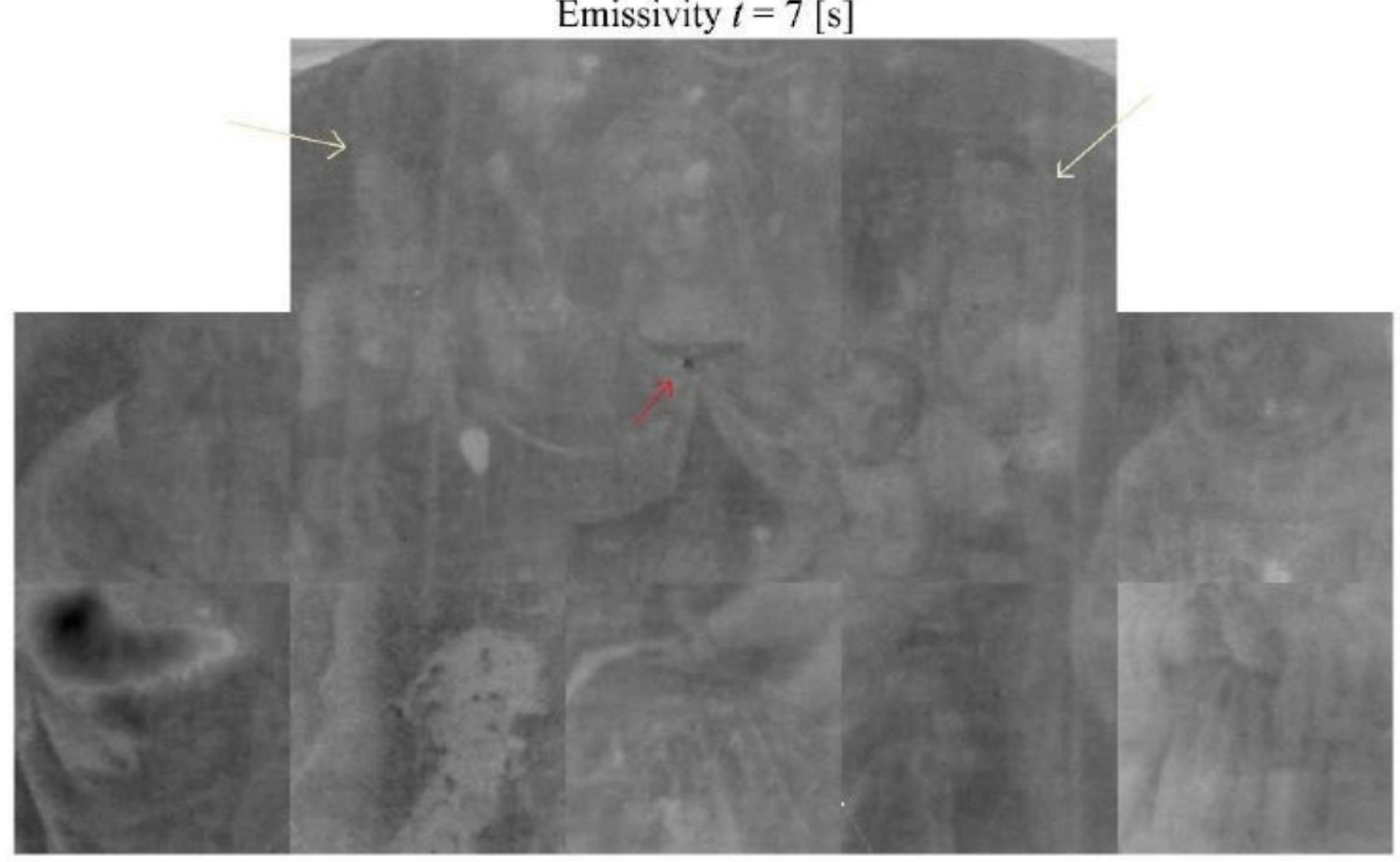

Figure 10

PuCT emissivity image obtained at $₫=7 \mathrm{~s}$.

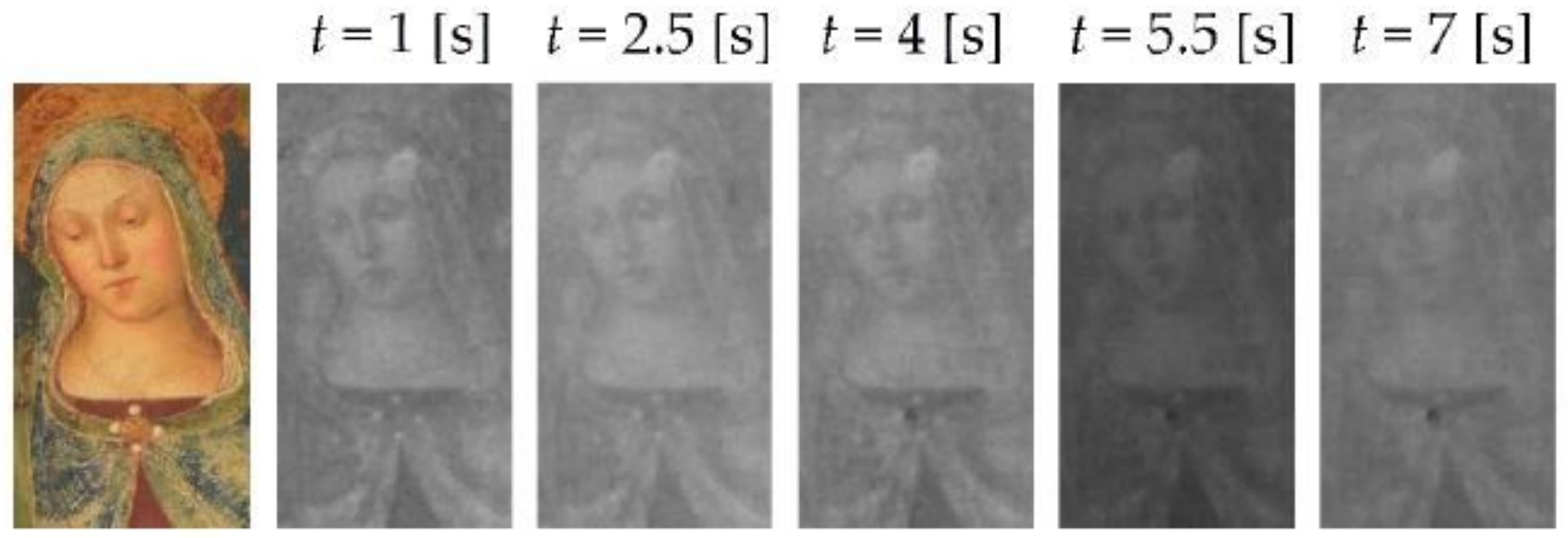

Figure 11 
PuCT emissivity images at different times representing Virgin's face and cloak closure. Darker areas corresponds to hotter areas.

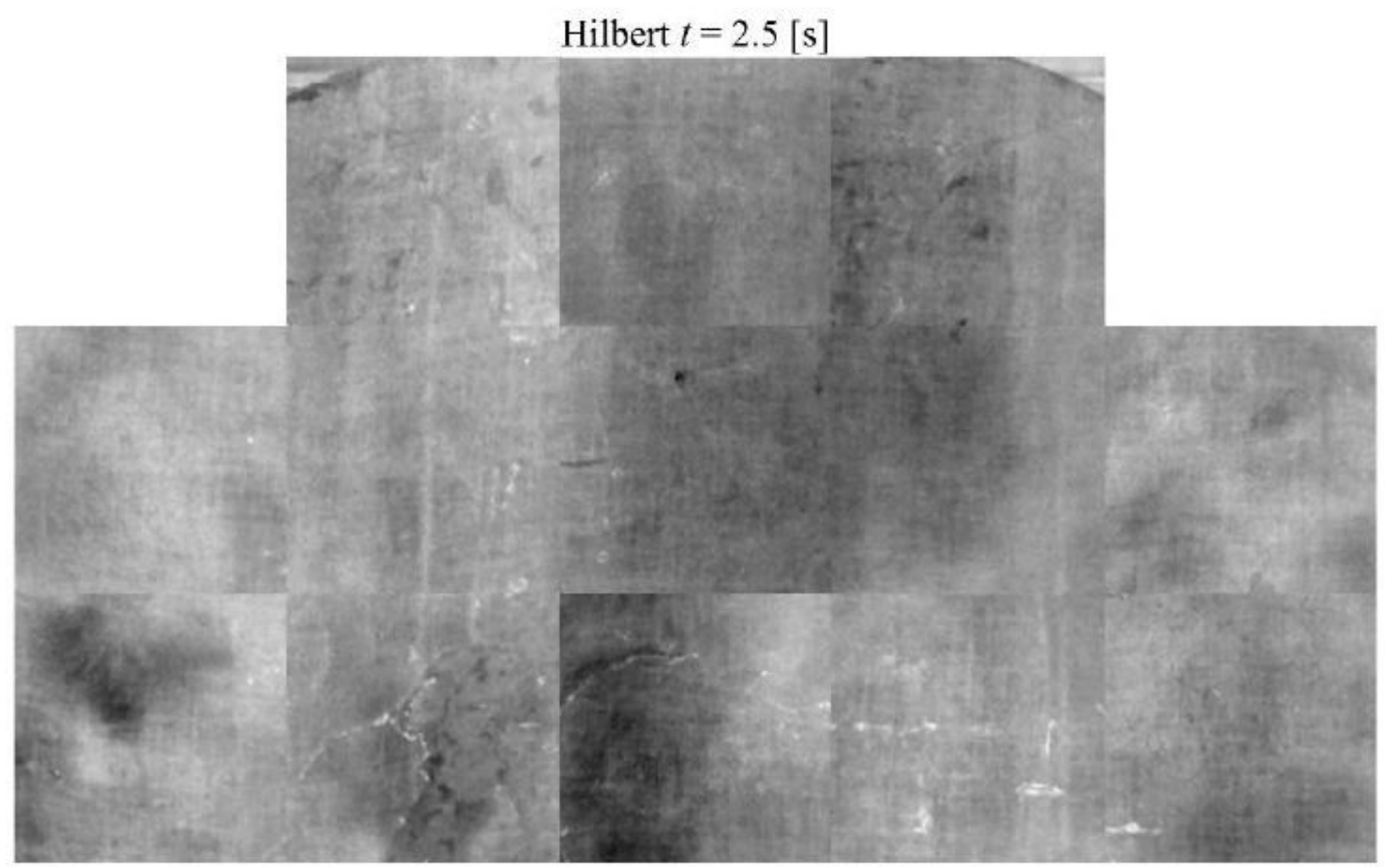

Figure 12

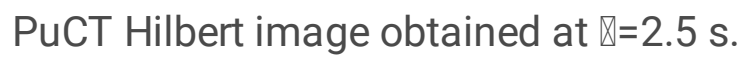




\section{Emissivity PCA1}

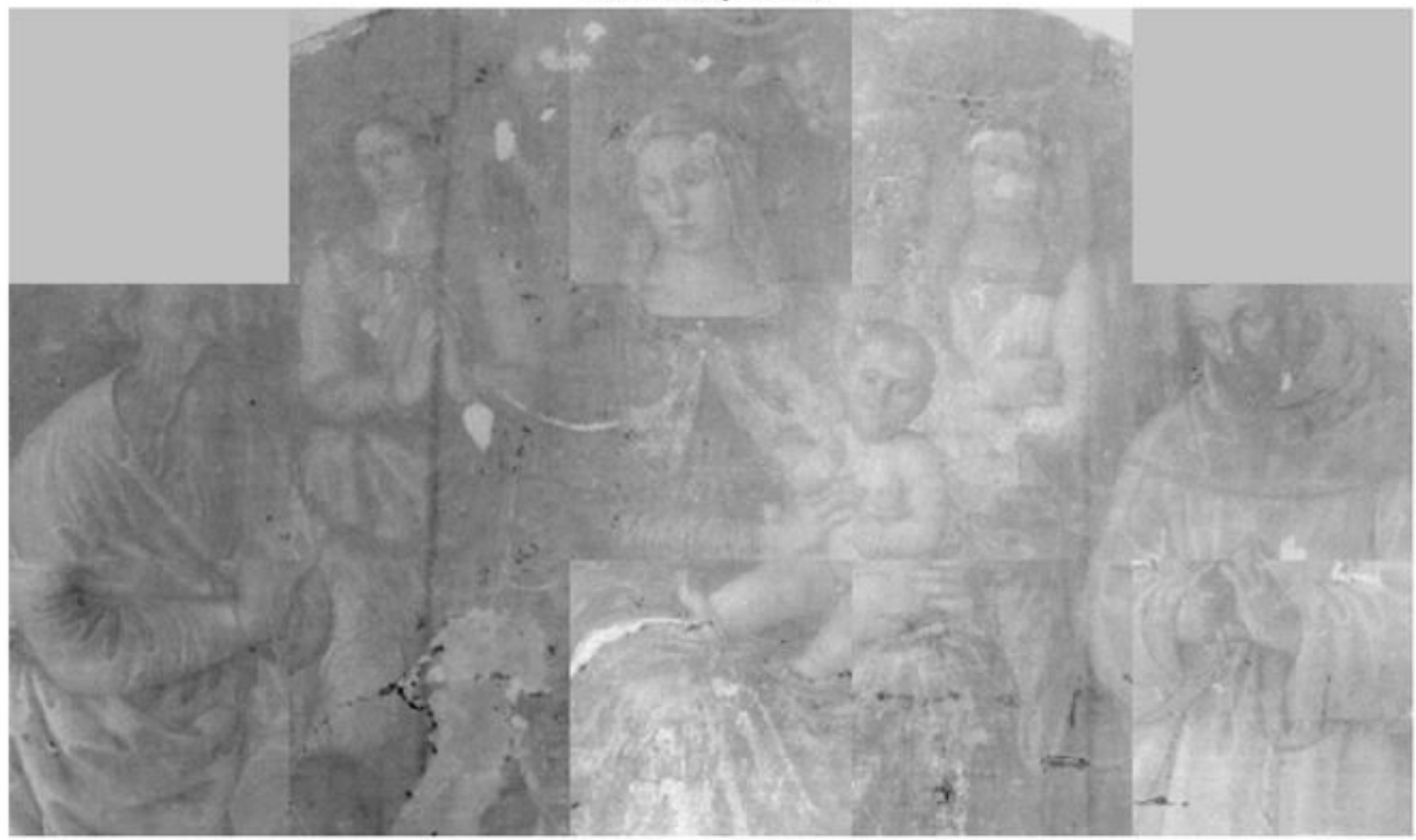

Figure 13

First PCA image retrieved by PuCT emissivity time series image. 


\section{Emissivity PCA2}

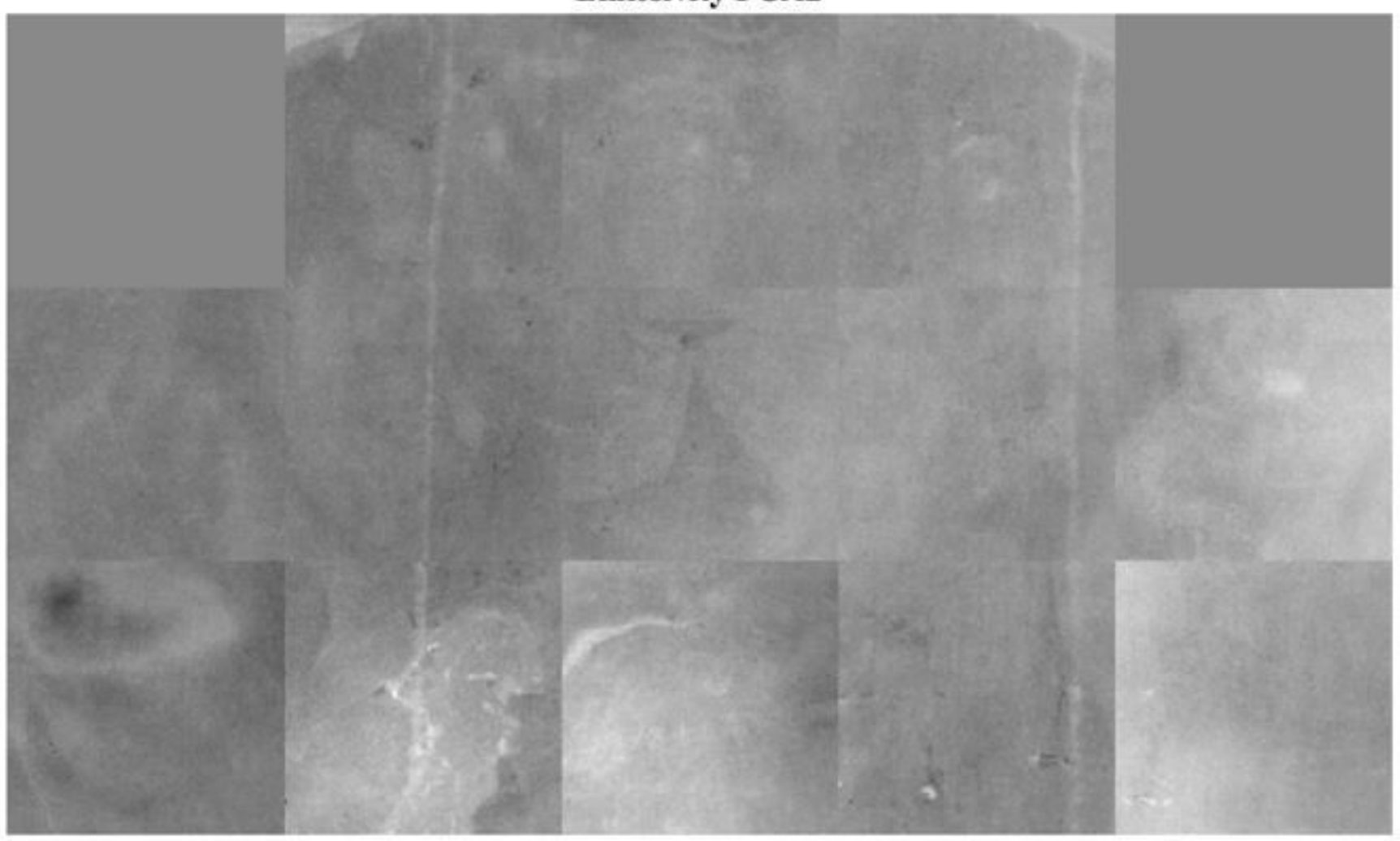

Figure 14

Second PCA image retrieved by PuCT emissivity time series image. 


\section{Emissivity PCA3}

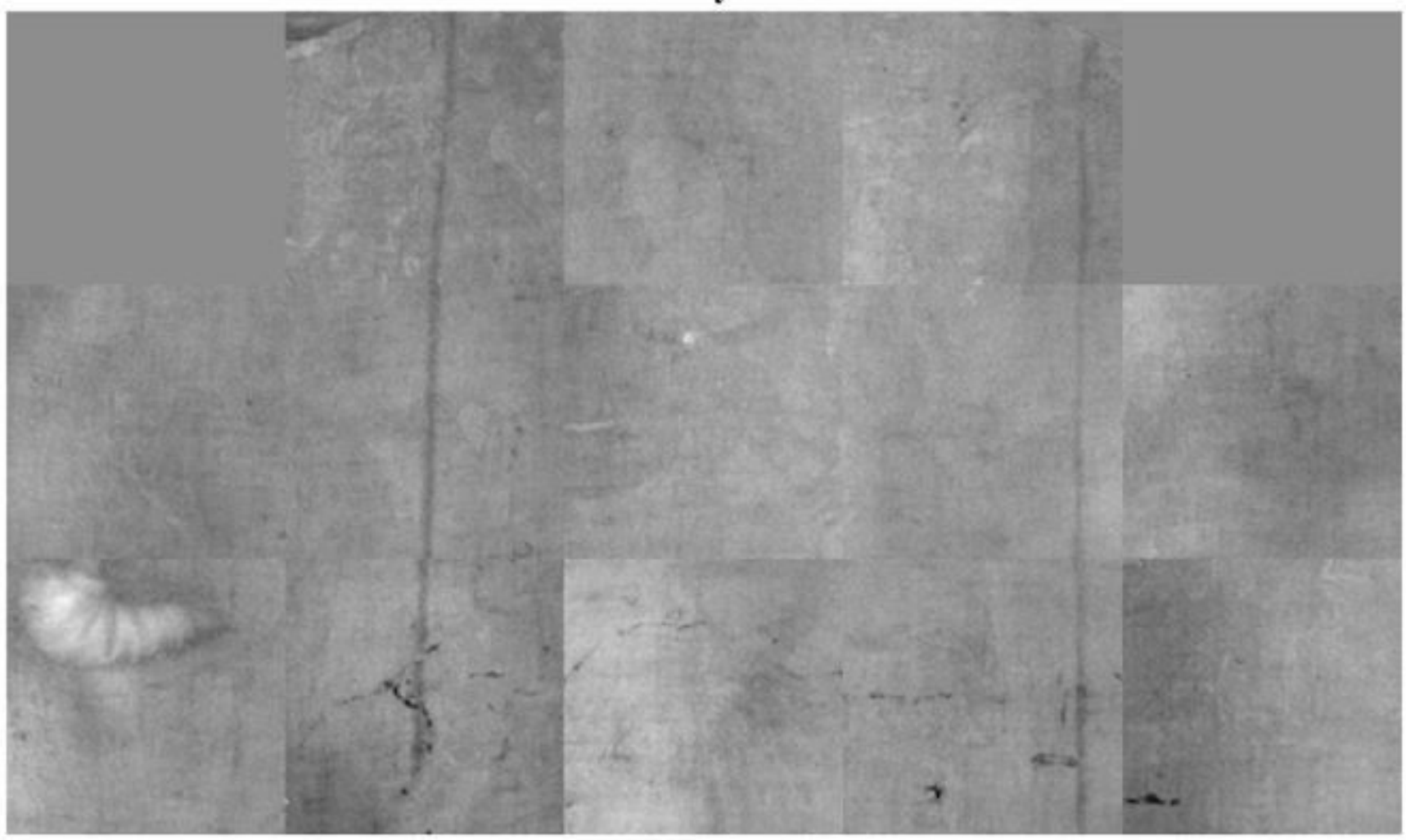

Figure 15

Third PCA image retrieved by PuCT emissivity time series image. 


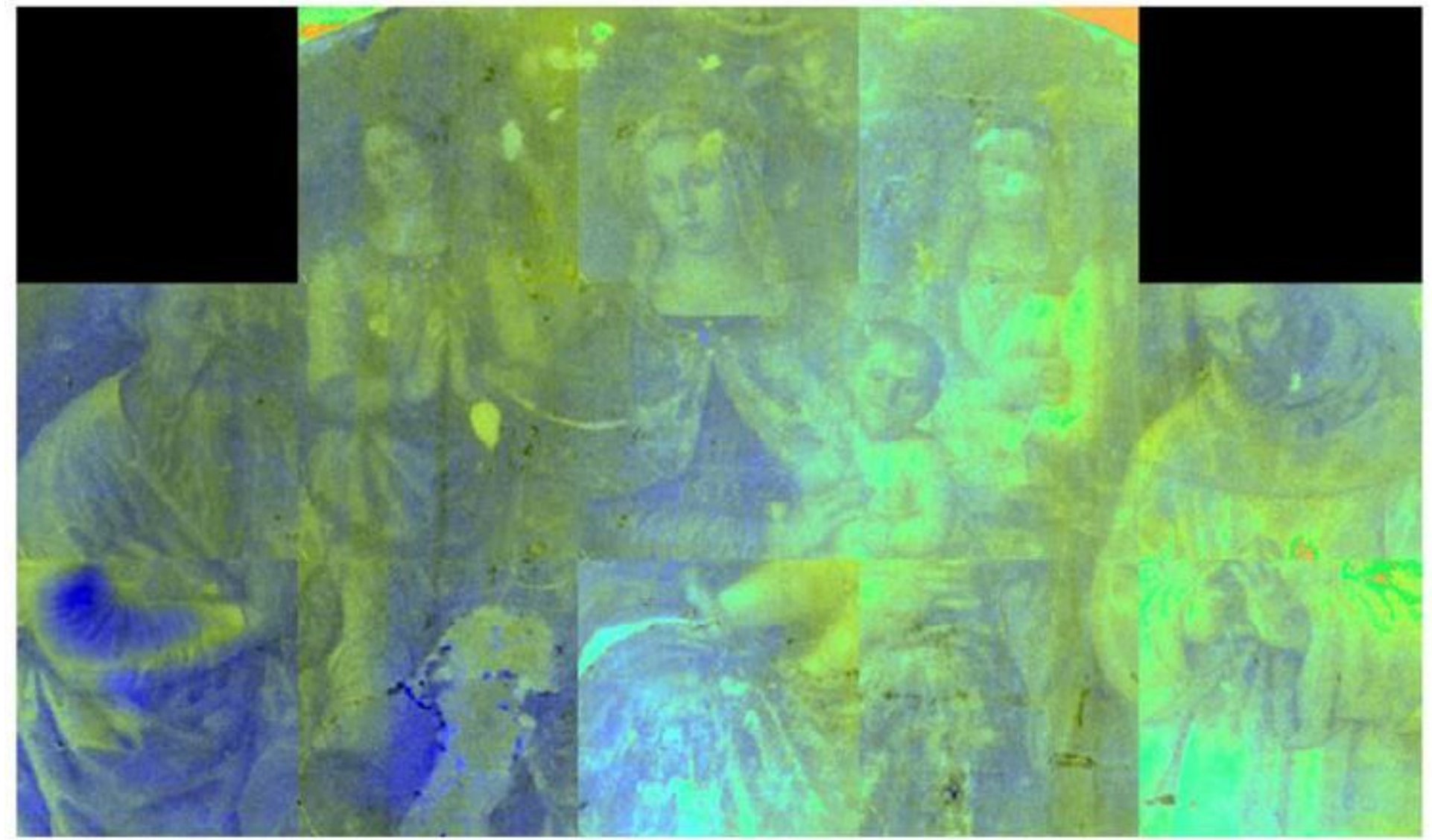

Figure 16

False-colour PuCT $-\mathrm{YCbCr}$ colour space at $\mathrm{t}=1 \mathrm{~s}$ PCA image retrieved by PuCT emissivity time series image. 

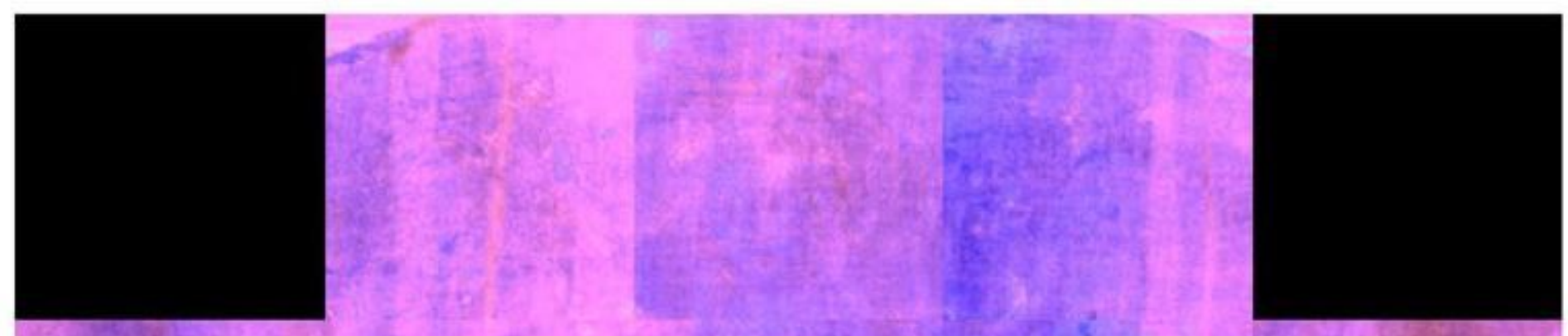

\section{Figure 17}

False-colour PuCT - YCbCr colour space at $\mathrm{t}=3 \mathrm{~s}$ PCA image retrieved by PuCT emissivity time series image. 

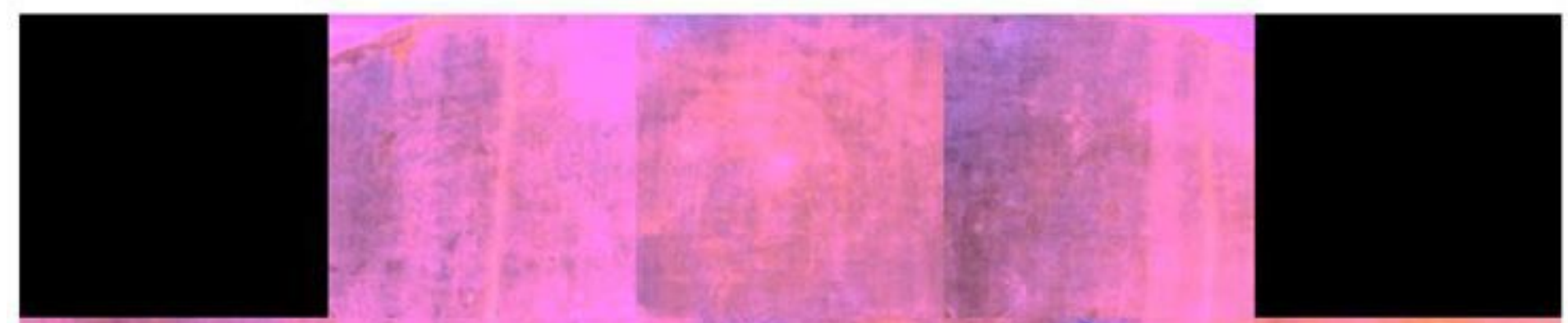

Figure 18

False-colour PuCT - YCbCr colour space at $\mathrm{t}=4 \mathrm{~s}$ PCA image retrieved by PuCT emissivity time series image. 